\title{
Belowground Microbiota and the Health of Tree Crops
}

\begin{abstract}
Jesús Mercado-Blanco ${ }^{1}$, Isabel Abrantes ${ }^{2}$, Anna Barra Caracciolo ${ }^{3}$, Annamaria Bevivino ${ }^{4 *}$, Aurelio Ciancio ${ }^{5}$, Paola Grenni ${ }^{3}$, Katarzyna Hrynkiewicz ${ }^{6}$, László Kredics ${ }^{7}$ and Diogo N. Proença ${ }^{8}$
\end{abstract}

\begin{abstract}
${ }^{1}$ Department of Crop Protection, Agencia Estatal Consejo Superior de Investigaciones Científicas, Institute for Sustainable Agriculture, Córdoba, Spain, ${ }^{2}$ Department of Life Sciences, Centre for Functional Ecology, University of Coimbra, Coimbra, Portugal, ${ }^{3}$ Water Research Institute (CNR-IRSA), National Research Council, Rome, Italy, ${ }^{4}$ Department for Sustainability of Production and Territorial Systems, Italian National Agency for New Technologies, Energy and Sustainable Economic Development (ENEA), Rome, Italy, ${ }^{5}$ Institute for Sustainable Plant Protection, National Research Council, Bari, Italy, ${ }^{6}$ Department of Microbiology, Faculty of Biology and Environmental Protection, Nicolaus Copernicus University, Toruń, Poland, ${ }^{7}$ Department of Microbiology, Faculty of Science and Informatics, University of Szeged, Szeged, Hungary, ${ }^{8}$ Centre for Mechanical Engineering, Materials and Processes (CEMMPRE) and Department of Life Sciences, University of Coimbra, Coimbra, Portugal
\end{abstract}

Trees are crucial for sustaining life on our planet. Forests and land devoted to tree crops do not only supply essential edible products to humans and animals, but also additional goods such as paper or wood. They also prevent soil erosion, support microbial, animal, and plant biodiversity, play key roles in nutrient and water cycling processes, and mitigate the effects of climate change acting as carbon dioxide sinks. Hence, the health of forests and tree cropping systems is of particular significance. In particular, soil/rhizosphere/root-associated microbial communities (known as microbiota) are decisive to sustain the fitness, development, and productivity of trees. These benefits rely on processes aiming to enhance nutrient assimilation efficiency (plant growth promotion) and/or to protect against a number of (a)biotic constraints. Moreover, specific members of the microbial communities associated with perennial tree crops interact with soil invertebrate food webs, underpinning many density regulation mechanisms. This review discusses belowground microbiota interactions influencing the growth of tree crops. The study of tree-(micro)organism interactions taking place at the belowground level is crucial to understand how they contribute to processes like carbon sequestration, regulation of ecosystem functioning, and nutrient cycling. A comprehensive understanding of the relationship between roots and their associate microbiota can also facilitate the design of novel sustainable approaches for the benefit of these relevant agro-ecosystems. Here, we summarize the methodological approaches to unravel the composition and function of belowground microbiota, the factors influencing their interaction with tree crops, their benefits and harms, with a focus on representative examples of Biological Control Agents (BCA) used against relevant biotic constraints of tree crops. Finally, we add some concluding remarks and suggest future perspectives concerning the microbiota-assisted management strategies to sustain tree crops.

Keywords: tree crops, belowground microbiota, biological control agents, endophytes, mycorrhiza, phytoparasitic nematodes, plant-growth-promoting microorganisms, soil-borne pathogens 


\section{INTRODUCTION}

Tree crops are fundamental for human nutrition and warrant food security and stability of many farms. The surface covered by tree crops showed a growing trend in the last decade, approaching to a global acreage of 10 Mha for main fruit types with an $\sim 20 \%$ increase in productivity during the period 20042014 (FAOSTAT, http://fenix.fao.org/faostat/beta/en/) (Figure 1). Plants (like trees) as well as the environment (such as soil) consist of complex and diverse assemblage of myriads of microbial species closely associated with their host, either as epiphytes or as endophytes (Trivedi et al., 2016). The association established by a plant and its microbiota (Lederberg, 2006) can be either stable, transient or fluctuating, enduring along the host lifetime determines its development, fitness, and health (Kowalski et al., 2015). The belowground microbiota is mostly comprised of bacteria and fungi belonging to the second trophic level (i.e., decomposers, mutualists, pathogens, parasites, and root-feeders) of the soil food web (Ingham, 1999) (Figure 2). Because of their size, nematodes per definition are not part of the soil microbiota, although they can play important roles in shaping its structure, including not only species belonging to the second trophic level (root-feeder nematodes) but also those ones of the third level (i.e., shredders, predators, grazers), particularly nematodes feeding on fungi and bacteria. Despite their parasitic behavior, phytoparasitic nematodes spend a considerable part of their lifecycle in the soil and represent the first group of plant parasites present in the soil. Therefore, the fraction of microorganisms linked to them can be considered as a specific compnent of the plant-associated microbiota (Vandekerckhove et al., 2000; Haegeman et al., 2009).
The study of the belowground microbiota has gained attention during the last years. Many studies have investigated soil belowground microbiota focusing on key issues such as the composition, structure, and functioning of these microbial communities and how they are built up and influenced by a range of factors [e.g., changing environment, varying weather/climatic conditions, (diffuse) pollution, anthropogenic actions, plant genotype, plant signals, etc.] [see, for instance (Doornbos et al., 2012; Bakker et al., 2013; Bulgarelli et al., 2013; Mendes et al., 2013; Lakshmanan et al., 2014; Fierer, 2017)]. Structural and functional modifications in the soil/rhizosphere microbiota have a crucial impact on aboveground ecosystems. In the particular case of trees, the trophic interactions established between the host and its associated belowground microbiota could be assumed, at least a priori, as more durable than that occurring in shortliving, herbaceous species. Indeed, due to their perennial, longliving nature, it could be envisaged that belowground microbial communities associated with tree crops may be shaped by more persistent changes than those taking place in annual crops. Trees provide, in a more long-lasting way, an energy flow through photosynthesis, mobilizing nutrients as part of a continuous process leading to their recycling via the organic matter accumulation and its eventual decay. Moreover, due to the absence of annual rotation and lack of soil tillage, perennial tree crops also represent a stable food source not only for building up consortia of beneficial microbial communities but also for many root pathogens or parasites. Direct effects, due to deposition of organic matter and nutrients, could be more constant while indirect effects through agricultural inputs (i.e., application of fertilizers, pesticides, etc., irrigation and soil labor) would potentially work in a similar way as in annual crops.

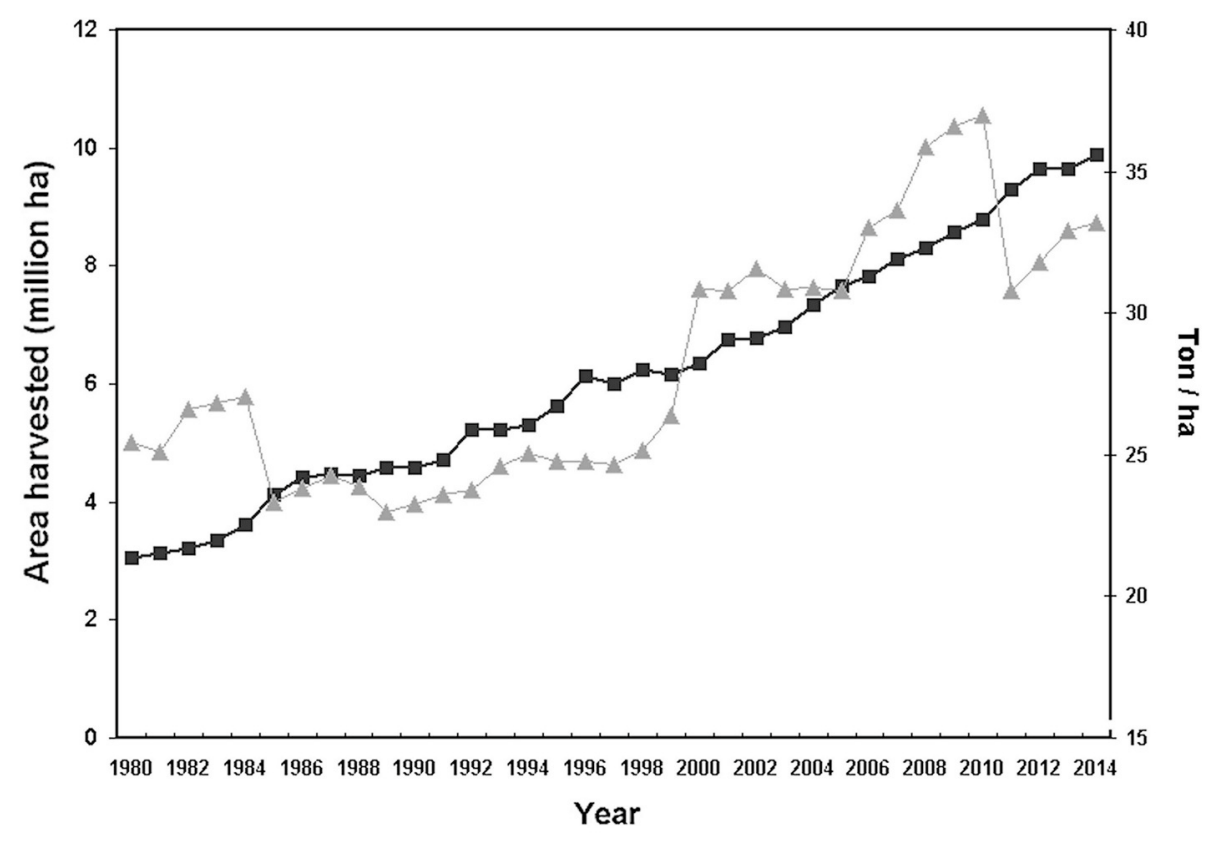

FIGURE 1 | Total world surface (triangles) and yield/hectar (solid squares) of main tree crops (citrus, fresh and tropical, pome and stone fruits) (source FAOSTAT: http://fenix.fao.org/faostat/beta/en/). 

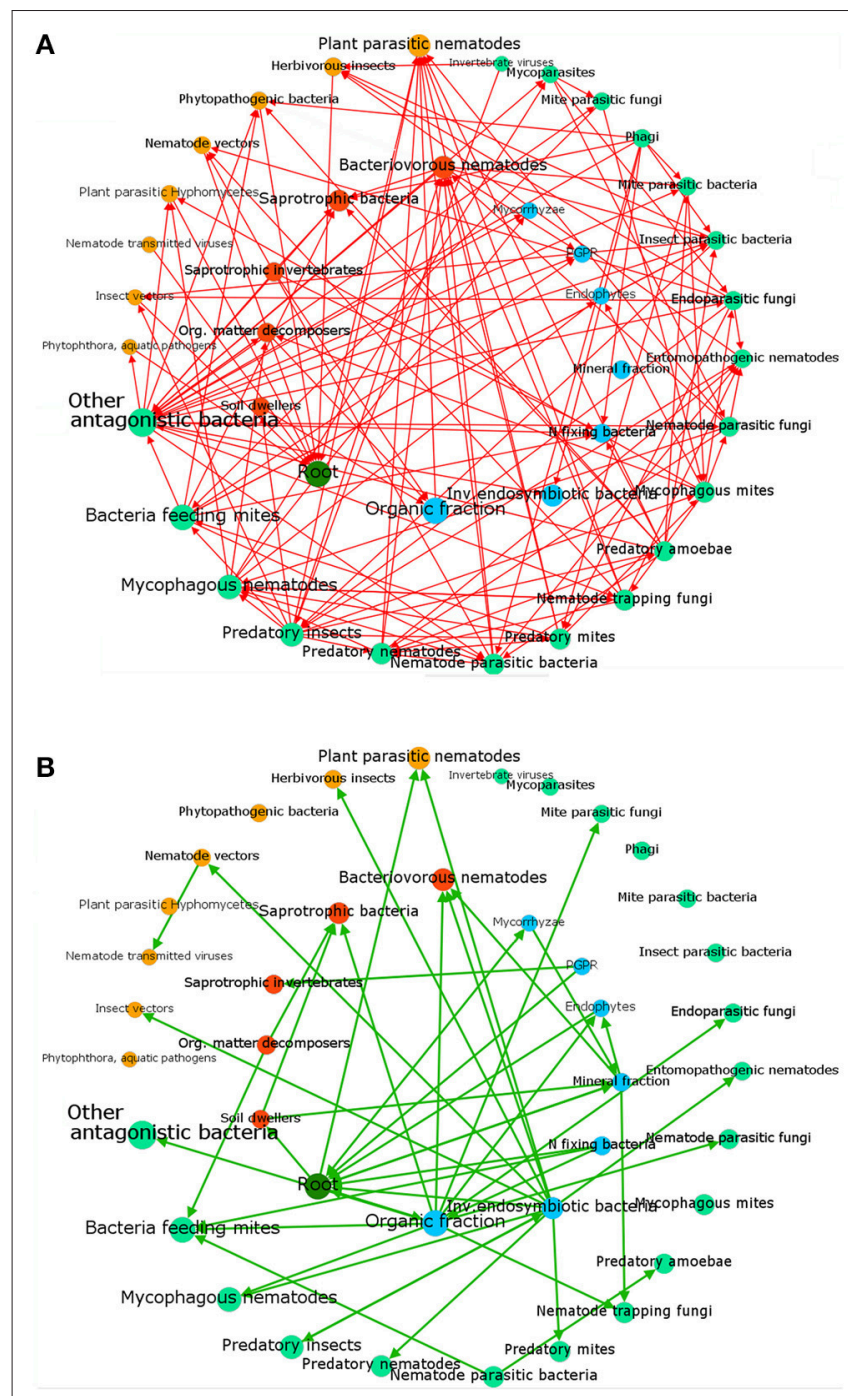

FIGURE 2 | A simplified food web describing main soil components and their relationships. The nodes are classified by roles as: primary root (dark green), beneficial soil components, organisms or promoters, including soil factors (blue), decomposers (brown), pathogens (orange) and biocontrol agents or antagonists (pale green). Arrows show negative effects (A), such as predation, parasitism, pathogenicity or (B) positive links, such as growth promotion, symbiosis or alimentary provision. Indirect factors such as those related to abundance, competition or other density-dependent effects are not included. Node labels and sizes are proportional to their connection level (number of edges). Analysis produced with Gephi (Bastian et al., 2009).

Being present on a time scale of years, and having a persistent, deeper root system, the impacts of tree crops (e.g., on nutrients mobilization, organic matter accumulation, parasites, etc.) largely differ from annual crops and thus cannot be considered as comparable. This is well illustrated by the currently-available and powerful metagenomic approaches (Colagiero et al., 2017). Overall, the events taking place between a tree crop and its associated whole soil microbiota have not been widely investigated.
In this study, we consider a tree crop as a woody, perennial plant with a distinct trunk, such as fruit, nut, and timber trees of economic importance, grown in orchards or in planted forests. Therefore, we exclude from this definition any palm "tree" species (Arecaceae family) as well as any other herbaceous perennial monocots (e.g., Musa spp., Dracaena spp., Poaceae family representatives, etc.) showing arborescent growth, since from both botanical and anatomical point of view they are not true trees. Tree crop ecosystems are of immense importance since they provide a range of products and ecosystem services. An increased understanding of the links between soil microbiota and trees is certainly helpful for the development of more effective and sustainable tree crop management strategies. Here, we (i) summarize methodological approaches used to unravel belowground microbial communities, with emphasis on tree crops; (ii) review the composition, distribution, and multitrophic networks of soil and root-associated microbiota, including endophytes, and the way they influence aboveground ecosystems in tree crops; (iii) examine the benefits (productivity, development, health and fitness, stress alleviation) and harms (mainly biotic stresses) for tree crops and woody plantations upon interaction with indigenous and introduced soil-borne (micro)organisms; and (iv) recapitulate strategies implemented for tree crop growth promotion.

\section{METHODOLOGICAL APPROACHES TO UNRAVEL THE COMPOSITION AND FUNCTION OF BELOWGROUND MICROBIOTA}

Methods to assess the diversity, structure, and function of microbial communities can be categorized into three main groups, namely conventional, biochemical and molecular. Here, we summarize the advantages and limitations of main methodological approaches to study the composition and function of rhizosphere microbial communities, with emphasis on tree crops (Table $\mathbf{1}$ ).

\section{Conventional and Biochemical Methods}

Culture-based methods constitute a good complement to DNAbased approaches. However, they are extremely biased regarding the actual evaluation of microbial genetic diversity since only $<1 \%$ of the total number of prokaryotic species present in the environment are culturable. Several improved procedures and media mimic natural environments in terms of nutrients, oxygen gradient, $\mathrm{pH}$, etc. maximizing the cultivable fraction of soil-borne microbial communities (Gravel et al., 2007). In addition, the number of colony-forming units (CFU) is positively correlated with enzymes and respiratory activity. This approach may be applied to characterize the relative abundance of active microorganisms with certain functions or trophic requirements (Blagodatskaya and Kuzyakov, 2013). Even though culturedependent methods are not ideal for evaluating the actual composition of natural microbial communities when used alone, they are useful for understanding growth habits, development, 


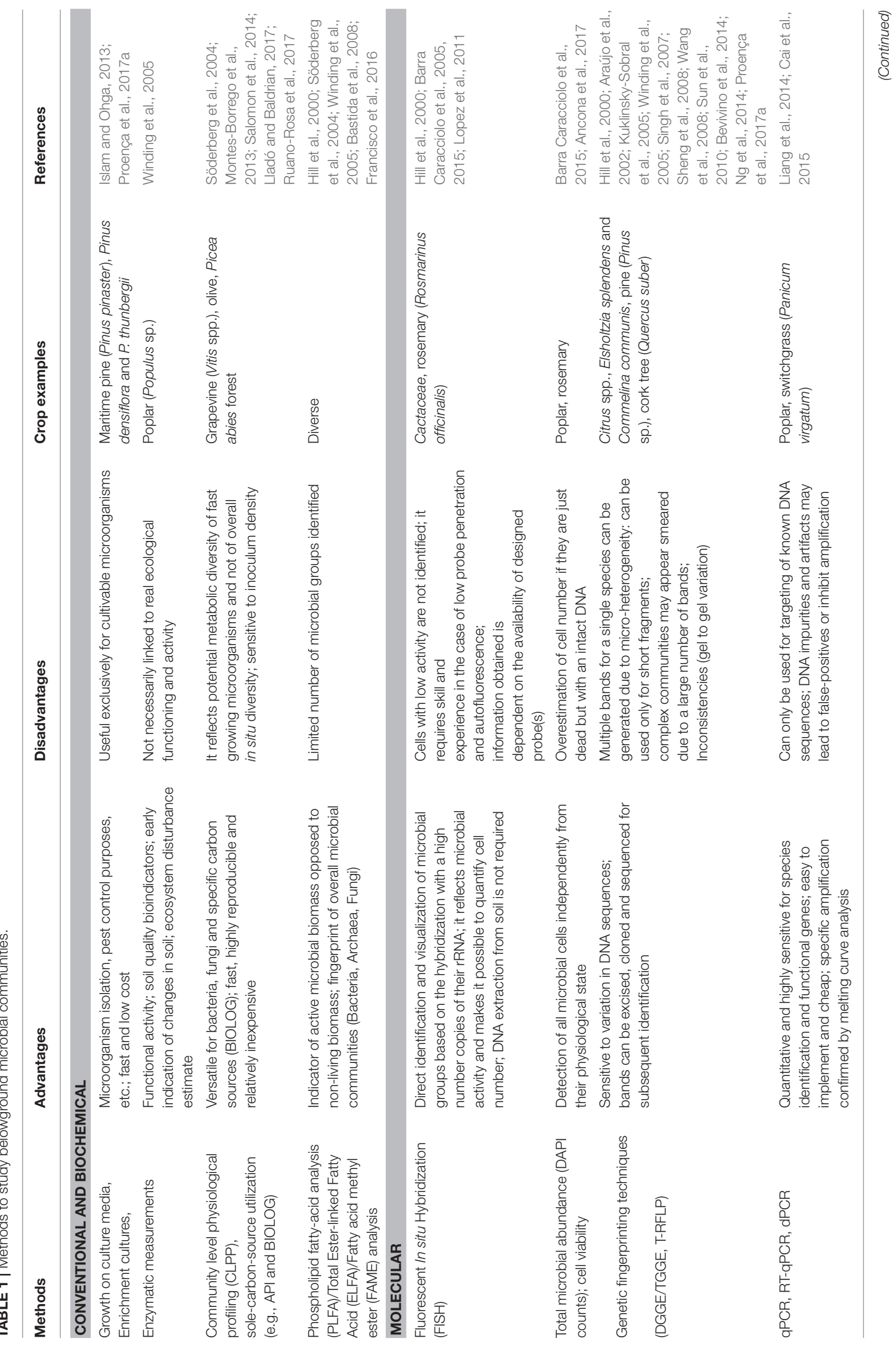




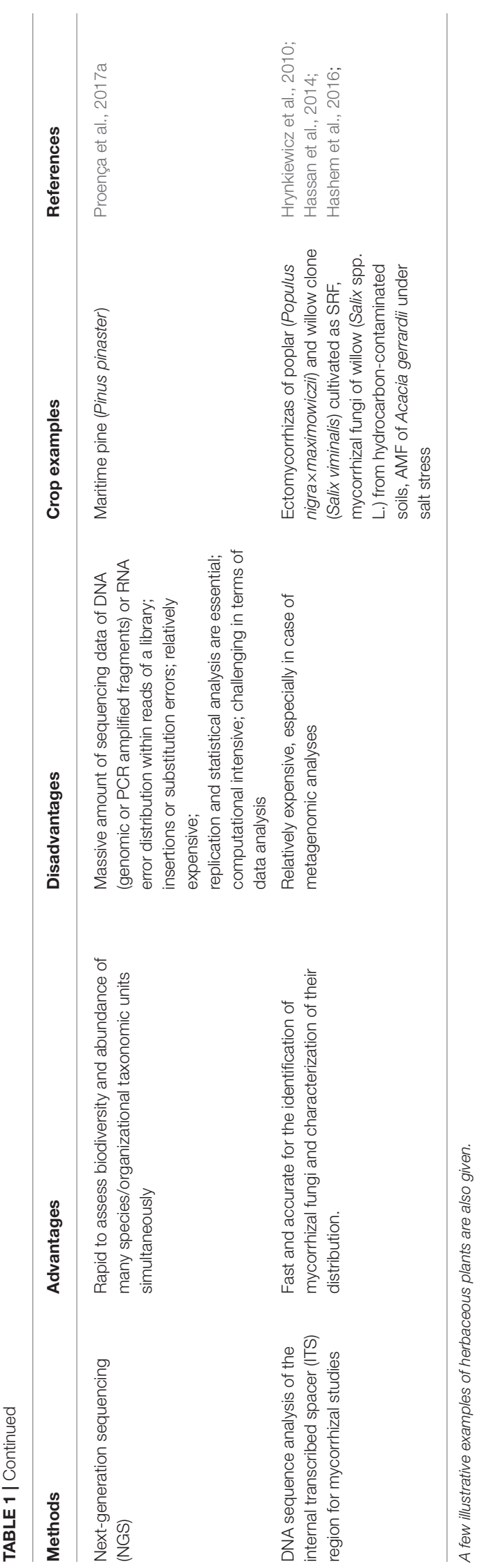

and potential functions of soil and rhizosphere microorganisms (VanInsberghe et al., 2013; Bevivino and Dalmastri, 2017).

Biochemical methods enable the assessment of soil microbiota activities of both the overall microbial community (e.g., dehydrogenase activity) and specific components (e.g., ammoniaoxidizing bacteria). The release of labile compounds, including enzymes, by living roots or lysis of root cells, stimulates microbial activity and growth in a similar way as rhizodeposits (Loeppmann et al., 2016). Consequently, localization of easily available C yields hotspots of microbial abundance and activities, frequently termed as the "rhizosphere effect" (Reinhold-Hurek et al., 2015; Thijs et al., 2016). Extracellular enzyme activities in the rhizosphere are higher compared to root-free soils, similarly to total microbial biomass and activity measured as respiration or growth rates (Allison and Vitousek, 2005; Ancona et al., 2017). Roots and associated mycorrhizal communities are known as major producers of $\beta$-glucosidases and acid phosphatases (Conn and Dighton, 2000). Despite soil enzymes being partly of plant origin, microorganisms constitute the main source of enzymes mediating the cycling of major nutrients (C, N, P, and S).

One approach to characterize the soil microbial communities is the Community Level Physiological Profiling (CLPP), in which species are identified based on utilization of different carbon sources with EcoPlateTM (Biolog, Inc.). CLPP yields information on both function and structure of part of a microbial community metabolically active under plate conditions (Garland and Mills, 1991). The BIOLOG ${ }^{\circledR}$ advantages include the identification of physiological profiles of a microbial community as a whole (Stefanowicz, 2006). However, most bacterial cells in natural ecosystems are inactive and the substrates available in BIOLOG $^{\circledR}$ plates are not necessarily relevant from the ecological point of view, and do not reflect the diversity of substrates found in the environment (Konopka et al., 1998). This methodology has been applied to compare functional diversity of communities from rhizosphere and non-rhizosphere soils (Söderberg et al., 2004), from rhizospheres of different plant species (Grayston et al., 1998), and to link microbial functional diversity of olive rhizosphere soil to management systems in commercial orchards (Montes-Borrego et al., 2013). While limitations of this methodology for the characterization of whole communities are well known, it continues to be used in combination with molecular approaches to identify the copiotrophic, fast-growing fraction of the bacterial community of soil environments as those from coniferous forests, where oligotrophic taxa are usually dominant (Lladó and Baldrian, 2017).

Biochemical methods can also be used to assess microbial community structure and to perform a phenotypic fingerprinting of the main groups (Gram-positive and Gram-negative bacteria, fungi, etc.) in the rhizosphere. This is the case of the phospholipid-derived fatty-acid (PLFA) and the total esterlinked fatty-acid (ELFA) methods (Sharma and Buyer, 2015; Hinojosa et al., 2016). As the fatty-acid side chains are rather unique among the various life forms, these molecules are widely used as taxonomic and phylogenetic biomarkers to describe the structure and size of microbial communities in soil and rhizosphere samples (Debode et al., 2016; Francisco et al., 2016). Phospholipid fatty-acids are found exclusively in cell membranes 
and not in other parts of the cell as storage products. This is important as cell membranes are rapidly degraded and the component PLFA is quickly metabolized following cell death. Consequently, phospholipids can serve as important indicators of active microbial biomass as opposed to non-living biomass. These methods are useful for assessing the structure of soil microbial communities and for determining effects of soil disturbances such as cropping practices, pollution, and changes in soil quality. For example, PLFA analysis was successfully used to investigate the impact of Populus spp. grown as short rotation coppice (SRC) on the microbial communities of arable soils (Baum et al., 2013).

\section{Molecular Methods}

Molecular methods have provided a more-in-depth understanding of the occurrence and phylogenetic diversity of soil microbial communities (Tiedje et al., 1999; Fakruddin and Mannan, 2013). Polymerase chain reaction (PCR)-based approaches are commonly used for phylogenetic assignments. Small subunit rRNA genes (for instance, the 16S small subunit ribosomal RNA [16S rRNA] for prokaryotic cells) are amplified from soil-extracted nucleic acids. Microbial rRNA gene sequences can then be sequenced and identified using appropriate databases (e.g., NCBI GenBank, EMBL, EzBioCloud, etc.) and compared with those of known microorganisms (Janssen, 2006). Similarly, the identification of soil fungi and fungal symbionts associated with previously selected and characterized mycorrhizas is based on sequence analysis of gene fragments from the large-subunit rRNA (LSU) or their internal transcribed spacer (ITS) regions (Porras-Alfaro et al., 2014). Taxonomic and phylogenetic affiliation of fungi can be based on widely available databases like the NCBI GenBank or on the stable and reliable platform UNITE, designed for sequence-based identification of ectomycorrhizal asco- and basidiomycetes.

Molecular-based approaches have revealed an extraordinary taxonomical and functional diversity of microorganisms. To study the population structures and dynamics of microbial communities, genetic fingerprinting techniques such as Denaturing Gradient Gel Electrophoresis (DGGE) were developed (Muyzer et al., 1993). Nowadays, DGGE can be used as a first approach to visualize main differences in a given microbial community and subsequently high-throughput sequencing (HTS) can be applied to have a deeper understanding of the microbiota composition (Di Lenola et al., 2017; Proença et al., 2017a). This methodology has been implemented in different fields and it is very common in soil microbiology studies (Bevivino et al., 2014; Ng et al., 2014), or to assess the aboveground microbial structure of trees (e.g., maritime pine, Pinus pinaster Ait.) (Proença et al., 2017a). Other community profiling techniques include temperature gradient gel electrophoresis (TGGE), single-strand conformation polymorphism (SSCP), terminal restriction fragment length polymorphism (T-RFLP), amplified rDNA restriction analysis (ARDRA), and amplified ribosomal intergenic spacer analysis (ARISA) (Anderson and Domsch, 1989; Anderson and Cairney, 2004). These methods can also provide detailed information about community structure in terms of richness, evenness and composition and permit to identify selected species and functional genes involved in specific processes. Nevertheless, these qualitative PCR-based methods do not provide information on the gene copy numbers. To achieve that, implementation of qPCR (quantitative PCR) is needed whereas RT-qPCR (reverse transcription $\mathrm{qPCR}$ ) is informative about the expression of a specific gene (Stella, 2014). However, the phylogenetic characterization of prokaryotic cells based on DNA extraction from soil does not reflect the activity of rhizosphere microbial community, as DNA may also proceed from dead or inactive cells. Likewise, the analysis of biodiversity based on the molecular identification of single ectomycorrhizal roots or arbuscular spores, and the application of cloning for identification of arbuscular mycorrhizal fungi (AMF), have some limitations difficulting a reliable portrait of the microcosm environment condition. Thus, a novel sequence-based method was developed to describe AMF communities, coupling the previously established AMF-specific PCR primers that amplify a c. 1.5-kb long and AMF-specific pSSU-ITS-pLSU fragment with single molecule real-time (SMRT) sequencing (Schlaeppi et al., 2016). Finally, substantial progress has been also made to facilitate the quantitative detection of individual nematode taxa on the basis of small subunit ribosomal DNA-based (SSU-rDNA) monitoring of nematode assemblages (Vervoort et al., 2012). In complex environments, such as soil, the newly developed digital polymerase chain reaction ( $\mathrm{dPCR}$ ) has been recently applied to quantify the absolute concentration of DNA targets or functional genes in soil (Kim et al., 2014; Cavé et al., 2016). This technology represents a promising tool enabling to examine the dynamics of soil microorganisms and to target pathogen-derived nucleic acids in environmental samples (Farkas et al., 2017).

\section{Epifluorescence Microscope-Based Methods}

Epifluorescence microscope-based methods do not need DNA extraction from soil, enabling direct visualization of microbial cells/structures under an epifluorescence microscope. The total direct count, cell viability (live/dead) and Fluorescence In situ Hybridization (FISH) are reliable and commonly used methods. The total direct count allows assessing microbial abundance through a DNA fluorescent intercalant such as DAPI, which can detect all microbial cells in a rhizosphere sample regardless of their physiological state and metabolic activity (Lew et al., 2010; Barra Caracciolo et al., 2015). Similarly, two fluorescent dyes, SYBR ${ }^{\mathrm{TM}}$ Green II and propidium iodide, can be used to discriminate between viable and dead cells (Ancona et al., 2017). Finally, FISH enables phylogenetic in situ identification and quantification of soil and rhizosphere communities at different phylogenetic levels (from domain to species), by using fluorescent labeled rRNA-targeted oligonucleotide probes in single cells. rRNA-targeted probes that occur in a large copy number detect specific sequences of rRNA in single cells. Since only viable and active cells possess a sufficient number of undamaged ribosomes, they act as indicators of the physiological state of cells (Di Lenola et al., 2017). The detection of FISH-stained cells can be hampered by strong soil 
background autofluorescence which is avoided by applying a density gradient centrifugation to extract the detachable bacteria from soil particles (Barra Caracciolo et al., 2005, 2010). FISH has been successfully applied in analyses of active microorganisms in the rhizosphere (Barra Caracciolo et al., 2015) including endophytes (Kutter et al., 2006; Lopez et al., 2011). The main limitations of this method are: (i) its inability to detect unknown species and those with low ability, or for which specific probes have not been designed yet, and (ii) probe's difficulty to enter into Gram-positive cells under specific conditions.

\section{Meta-Omic Approaches}

The recent development of HTS-based metagenomic analyses has further contributed to unveil either microbial or plant functioning in the rhizosphere, to yield a global view of the structure and diversity of the rhizosphere microbiota (Leveau, 2007; Barberán et al., 2012; Lindahl et al., 2013; Mendes et al., 2013; Hassan et al., 2014). The implementation of genomic methods to microbial assemblages is commonly used to describe communities overcoming biases inherent to PCR amplification of a single gene. The classical metagenomic strategy, as defined by Handelsman and colleagues (Handelsman et al., 1998), involves the following steps: DNA isolation, fragmentation and cloning, library screening, sequencing of interesting clones, and DNA comparison. Actually, three major and often overlapping directions can be recognized: the first trend aims at linking phylogeny to function; the second involves the discovery of genes or functions of interest; and the third is the mass sequencing of environmental samples which offers a more global (or systemsbiology) view of the community under study (Steward Rappé and Rappé, 2007).

The HTS or next-generation sequencing (NGS) technology is experiencing a rapid development, providing wide and indepth views in metagenomics. Several protocols and tools, including bioinformatic resources, are available for these studies. A number of HTS platforms have been developed and are widely used, including the Illumina (e.g., HiSeq, MiSeq), Roche 454 GS FLX+, SOLiD 5500 series, and Ion Torrent/Ion Proton platforms. Currently, the majority of microbial ecology studies implement HTS by focusing on either targeted gene sequencing with phylogenetic or functional gene targets or on shotgun metagenome sequencing (Pervaiz et al., 2017).

Most of the bacterial community studies have depended on a single gene, such as the hypervariable regions of the 16S rRNA gene, to assess taxonomic diversity and to determine which bacteria are present in a community. Other useful targets for bacterial community studies based on single amplicon sequencing include the type I chaperonins (cpn60 gene) (Links et al., 2012). However, these "metabarcoding" methods (sensu stricto they cannot be considered as metagenomic approaches since they are just based on libraries of single amplicons) are limited by short read lengths, sequencing errors, differences arising from the different regions chosen, and difficulties in assessing operational taxonomic units (OTU). Shotgun metagenomics sequencing avoids many of the biases encountered in amplicon sequencing because it does not require amplification prior to sequencing (Fierer et al., 2012; Sharpton, 2014). Application of metagenomic analysis also paves the way for scientists to build fundamental knowledge on fungal communities in the environment. Actually, the metagenomics assessment of fungal diversity is common not only for soil but also for plant samples (mycorrhiza, endophytes), enabling detailed determination of all fungal trophic groups: saprophytic, pathogenic, endophytic, and symbiotic (Lindahl et al., 2013).

Further technologies such as the nanopore sequencing (with mini flow cells such as the MinIon ${ }^{\mathrm{TM}}$ by Oxford Nanopore ${ }^{\mathrm{TM}}$ ), or the PacBio ${ }^{\mathrm{TM}}$ sequencing based on ionic readings are gaining popularity due to their capability to sequence very long reads (up to several kilobases) in milliseconds and without amplification (Branton et al., 2008; Singer et al., 2016). Some of these novel approaches are promising, since they combine easy use and/or portability with a massive data production. They have the potential to sequence all the retrotranscribed rDNA molecules present in a sample, thus accounting for a direct identification of active species. In the light of experimental assays applied to plants, the information that may be gained through these studies are higher than the limits considered a few years ago, and often exceed the analytical potential of the bioinformatic resources eventually applied.

By using the above methodological approaches, the diversity, structure, and functioning of fungal and bacterial communities, endophytic and/or rhizospheric, were studied in tree species including Populus deltodies (Gottel et al., 2011; Shakya et al., 2013), native forest species (Buée et al., 2009), and conifers (Baldrian et al., 2012; Proença et al., 2017a). For instance, these studies were instrumental to link the so-called core (bacterial) microbiota to specific ecological niches in a given species and, more importantly, under field-grown conditions (Beckers et al., 2017). Based on sequencing data it is also possible to predict the function of a microbial community by using the bioinformatic tools PICRUSt (Langille et al., 2013) and tax4fun (Aßhauer et al., 2015).

Metatranscriptomics, in which total environment RNA is sequenced, is applied to reveal and compare active community members and metabolic pathways (Urich et al., 2008; Turner et al., 2013). Although the analysis of total rRNA has been widely used to profile microbial communities in soil (Carvalhais et al., 2012), the gene expression of microbes in the rhizosphere is much less studied due to the difficulty to obtain sufficient material under controlled conditions from a highly variable and irregular niche. Nevertheless, metatranscriptomics has been used to identify genes expressed by eukaryotes in forest soils, to study the fungal and bacterial responses to $\mathrm{N}$ deposition in two forests dominated by sugar maple (Acer saccharum Marsh), or to analyse ectomycorrhizal roots and the genes active in the PilodermaPinus symbiosis (Damon et al., 2012; Liao et al., 2014; Hesse et al., 2015). Finally, the sensitivity of current metabolomic platforms represents an important constraint showing that this approach cannot solve all rhizosphere-signaling relations such as chemical communications and interactions (van Dam and Bouwmeester, 2016). 


\section{FACTORS INFLUENCING BELOWGROUND MICROBIOTA ASSOCIATED WITH TREE CROPS}

A long-living host may establish a durable interaction with its associated microbiota compared to that taking place in annual and/or herbaceous plants. Nevertheless, the composition and structure of the associated microbiota in any given tree crop undergo alterations along time and space due to factors such as environmental (sudden/long-term) changes, physical-chemical soil properties, anthropogenic actions, agronomical practices, climatic factors, plant developmental stage, (a) biotic stresses, etc. Depending on the tree crop under study, this range of factors may have either major or minor influence on the entire belowground microbial communities or on some of their specific components (Caliz et al., 2015).

Temperature and precipitation along with seasonal variations are among the main climatic/weather components controlling microbial growth and reproduction; therefore, these abiotic factors may substantially influence the soil microbiota of tree crop plantations and forests. Okada and colleagues found that autumn precipitation in the preceding year was a crucial factor influencing the biomass of ectomycorrhizal fungi (EMF) in a 40/50-year-old Pinus densiflora L. forest, while soil water availability for EMF and host plant roots in the growing season could positively impact ectomycorrhizal biomass in subsequent seasons (Okada et al., 2011). With the aim of simulating realistic future drought conditions, Felsmann and colleagues studied the effects of reduced precipitation for one growing season on the bacterial community of beech (Fagus sylvatica L.) and conifer forests (Felsmann et al., 2015). They found that moderate drought induced by the precipitation manipulation treatment significantly affected the active but not the total bacterial community, proposing that there is an adequate resistance of the soil microbial system over one growing season. In soils of a temperate beech forest, seasonality, resource availability and climatic factors (temperature and moisture) affected the community structure and abundance of Archaea and Acidobacteria indicating the high metabolic versatility and adaptability of these prokaryotic groups to environmental changes (Rasche et al., 2011). Finally, the effects of annual and interannual environmental variability of temperature, precipitation and chemical resources on soil fungi associated with an old-growth, temperate hardwood forest were investigated (Burke, 2015). Fungal communities were found to significantly vary by the season, sampling location, and depth with differences being consistent between years. Fungal species within the community were not consistent in their seasonality or preference for certain soil depths, but some of them were found to be consistently correlated with soil chemistry across the sampled years.

The soil properties are modified by a range of processes occurring during tree growth, which in turn affect rhizosphere microbial communities. Plant roots can influence the surrounding soil and inhabiting organisms (Lakshmanan et al., 2014). Roots release low-molecular-mass compounds (e.g., sugars, amino acids and organic acids), polymerized sugar, root border cells, and dead root cap cells. These rhizodeposits are used as carbon sources by soil microorganisms and can also contain secondary metabolites, such as antimicrobial compounds, nematicides, and flavonoids that are involved in establishing symbiosis or in warding off pathogens and pests, thereby acting as a crucial driving force for multitrophic interactions in the rhizosphere (Bais et al., 2006; Oldroyd, 2013). Experimental data from citrus crops parasitized by the insect pest Diaprepes abbreviatus in Florida showed that roots release specific volatile organic compounds (VOC) that attract entomopathogenic nematodes (EPN), with beneficial effects observable on the pest regulation. Also, plant-parasitic nematodes (PPN) revealed a positive tropism toward parasitized roots, mediated by one or more of the VOC components (Ali et al., 2010, 2011, 2013). This effect may be also significant for the microbiota associated with these nematode groups because several microbial species with a beneficial impact are passively dispersed by EPN and PPN. Soil pH, another important driver of soil microbial communities, can locally increase or decrease by up to two units in the rhizosphere due to the release and uptake of ions by roots (Hinsinger et al., 2009). Water uptake and root respiration affect soil oxygen pressure, thereby influencing microbial respiration. Soil nutrient availability can be modified in the rhizosphere by plant uptake and by the secretion of chelators, such as phytosiderophores, to sequester metallic micronutrients (Philippot et al., 2013).

The host plant can be considered as the primary biotic factor influencing the composition of soil microbiota associated with tree crops. The plant cover and crop types have an impact on the belowground microbial diversity, as shown by studies on soil metagenomes (Uroz et al., 2016; Colagiero et al., 2017). Structure and composition of fungal and archaeal communities proved to be dependent on the tree species, while bacterial communities differed between bulk soil and the rhizosphere but not between host trees. Similar results were obtained by Urbanová and collegues who demonstrated that fungal communities were strongly related to tree species while bacterial communities rather to root exudates (Urbanová et al., 2015). The composition of the nematode community in the rhizosphere soil is also influenced by the host genotype, as revealed by studies performed in olive (Palomares-Rius et al., 2012). Nematodes are also among the biotic factors influencing the composition of soil microbiota associated to tree crops, as shown by the differences induced on the AMF communities colonizing galls and roots of peach, Prunus persica (L.) Batsch, infected by the root-knot nematode Meloidogyne incognita (del Mar Alguacil et al., 2011).

Regarding anthropogenic factors, pollution caused by industrial and mining activities can shape microbiota associated with tree crops and timber trees. The effects of long-term metal pollution on soil microbial communities were evaluated along two soil gradients of forests with Scots pine, P. sylvestris L., and common beech as the dominant tree species (Azarbad et al., 2015). Metal pollution significantly affected bacterial community structure causing changes in the relative abundance of specific bacterial taxa resilient to metal pollution and increased frequency of certain metal-resistance genes, suggesting a link 
between microbial community composition and their functional potential in long-term polluted forest soils. The activity of timber harvesting was also shown to exert a significant and persistent effect on soil bacterial and fungal communities in Northern coniferous forests via organic material removal and soil compaction (Hartmann et al., 2012). Among the components of microbiota, plant symbionts like EMF and saprobic taxa of bacteria and fungi were the most sensitive to harvesting disturbances. The diversity and structure of soil bacterial and fungal communities remained significantly altered by harvesting disturbances, even more than a decade after harvesting. A subsequent study (Hartmann et al., 2014) revealed that physical soil disturbance during logging-associated compaction induced profound and long-lasting changes in the forest soil microbiota and associated soil functions, significantly reducing bacterial and fungal abundance, increasing alpha diversity and persistently altering the microbiota composition with a maximum impact observed 6-12 months after compaction. Fungi were less resistant and resilient than bacteria, with ectomycorrhizal species detrimentally affected by compaction, while saprobic and parasitic fungi were proportionally increased. Bacteria capable of anaerobic respiration, including metal, sulfur, and sulfate reducers from Proteobacteria and Firmicutes, were found to be significantly associated with compacted soils. Agronomical management systems also greatly influence the structure and functioning of soil microbial communities associated with tree crops. For instance, Montes-Borrego et al. (2013) revealed in a comparative analysis of organic and conventional olive farming systems in southern Spain, how management practices affected the chemical and biological soil properties indicating that olive orchards under organic management exhibited higher microbial diversity compared to conventionally managed orchards. The structure and diversity of phytoparasitic nematode communities infesting olive orchards are also, but not exclusively, influenced by soil management practices (Palomares-Rius et al., 2015). Indeed, this study concluded that soil physicochemical factors such as texture, $\mathrm{pH}$, and extractable $\mathrm{K}$, the climatic parameters minimum and maximum temperatures, and olive cultivar as the key agronomic variable were factors driving the population levels and community structure of olive phytoparasitic nematodes. An advanced citrus production system with daily fertigation rates have been applied in Florida to contrast the bacterial disease huanglongbing, by shortening the trees production cycle. This system increased the densities of some microbial antagonists of PPN such as Catenaria or other parasitic fungi, associated to a higher root biomass. However, some effects were also found on the densities of EPN, which showed opposite responses for steinernematid or heterorhabditid species (Campos-Herrera et al., 2014).

\section{BELOWGROUND MICROBIOTA AND TREE CROPS: BENEFITS AND HARMS}

Beneficial soil/root microbiota can promote plant growth directly (i.e., biofertilization, phytostimulation) and/or indirectly (i.e., suppressing plant diseases and pests). Alleviation of stress due to environmental pollutants or heavy metals [i.e., (phyto)rhizoremediation)], drought or salinated soils, are mediated by the activity of the plant-associated microbiota. Trophic interactions established between the host plants and their associated microbiota at the root level provoke effects influencing aboveground ecosystems. Moreover, longterm associations (i.e., nodule-forming bacteria able to fix $\mathrm{N}_{2}$, ecto- and endomycorrhizal symbioses, non-symbiotic plantgrowth-promoting rhizobacteria [PGPR] and fungi [PGPF], endophytes, etc.) may influence aboveground ecosystems in ways other than direct plant growth promotion. Successful associations should be based on the capacity of the microbes to modulate the plant host immunity. The dialogue established between plants and (components of) their microbiota are likely variations of a common theme where the boundaries among symbiotic, pathogenic or endophytic associations are, indeed, fuzzy (Zamioudis and Pieterse, 2012; Mercado-Blanco and Lugtenberg, 2014). Responses triggered in the plant as a consequence of the interactions taking place at the root level have an effect on aerial parts. Induction of systemic defense responses is a clear example that may affect plant health by triggering an enhanced resistance status against a range of phytopathogens and/or pests (Pieterse et al., 2014). The challenge is to understand these responses and how they disturb aboveground ecosystems, individuals or specific plant organs.

\section{Benefits}

\section{Mycorrhiza}

Most of the known tree crops, i.e., fruit trees cultivated in orchards (e.g., olive, apple, Malus domestica L., pear, Pyrus sp., cherry, Prunus sp., plum, P. domestica L., peach, apricot, $P$. armeniaca L., etc.) or fast growing tree species cultivated in SRF systems for biomass production (e.g., willow, poplar, alder, Alnus sp., ash, Fraxinus sp., birch, Betula sp., eucalyptus, Eucalyptus sp., etc.) form stable symbioses with mycorrhizal fungi. Tree crops can form two types of mycorrhizas differing in morphology: ectomycorrhizas (EM) or arbuscular mycorrhizas (AM). Moreover, some tree crops can form dual EM/AM (e.g., willow, poplar), although a trend toward greater fractional colonization with EM and lower colonization with vesiculararbuscular mycorrhiza (VAM) has been observed (Moyersoen and Fitter, 1999). Mycorrhizal fungi promote plant growth, aid nutrient uptake (reduced fertilizer requirement), increase yield, reproductive success and tolerance to abiotic (e.g., pollution, drought, salinity) and biotic (pathogens, herbivores, low microbial diversity in the soil) stresses, thereby improving field survival and establishment (Allen, 2006; Hrynkiewicz and Baum, 2012; Al-Karaki, 2013; Khabou et al., 2014; Manaut et al., 2015). Therefore, tree crops with well-established mycorrhizal symbiosis are characterized by increased adaptation level to edaphic parameters observed under unfavorable soil conditions. Direct and indirect beneficial effects of mycorrhizal fungi on plant growth and development are summarized in Figure 3.

Noteworthy, positive effects of mycorrhizal fungi on fruit tree growth can be detected only a few years after planting. 
Benefits of belowground microbiomes on tree crops

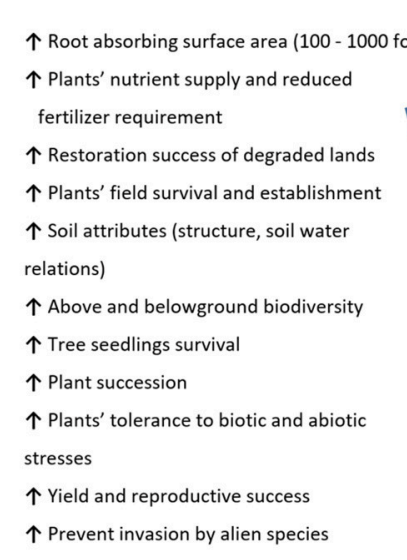

$\uparrow$ - increase; $\downarrow$ - decrease; AMF - arbuscular mycorrhizal fungi; EMF - ectomycorrhizal fungi, ACC - 1-aminocyclopropane-1-carboxylate; ROS - reactive oxygen species

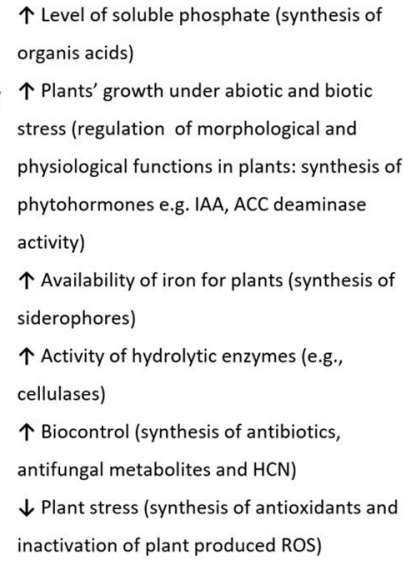

\author{
.
}

FIGURE 3 | Summary of the benefits that belowground microbiota (or some of their components) may confer to tree crops.

Indeed, during the first year of a tree growing in an orchard, it may happen that mycorrhizal fungi use some nutrients that could nourish the tree's own growth (Borkowska, 2002). In the case of ectomycorrhiza associated to Salix viminalis, a stronger growth of the plant can be already observed three months after EMF occurrence (Hrynkiewicz et al., 2012). Beneficial effects of mycorrhizal symbiosis may vary considerably between fungal and plant species, and with environmental conditions (e.g., physicalchemical soil parameters, climate, etc.).

Mycorrhizal associations of fast-growing trees play also a key role in host tolerance to unfavorable soil conditions, increasing phytoremediation efficiency of heavy metals and organic contaminants (Vervaeke et al., 2003; Baum et al., 2006). The most numerous group of EMF symbionts, along with the highest level of EMF colonization, observed in natural stands of tree crops, belong to orders Thelephorales (Tomentella sp.), Pezizales (Tuber sp., Geopora sp.) and Agaricales (e.g., Hebeloma sp., Cortinarius sp.). The mechanisms of action responsible for tolerance of EMF to adverse environmental conditions are not yet fully understood. Some results suggest that melanin or thelephoric acid present in the fungal mycelium can act as a protective interface between fungal metabolism and (a)biotic environmental stressors. Species of Geopora have been found to be the principal EMF symbionts of willows planted for restoration in fly ash, with high potential to survive under harsh environmental conditions (Hrynkiewicz et al., 2009; Gehring et al., 2014). Ectomycorrhizal associations, dominated by Tomentella sp., Hebeloma sp., Geopora sp. and Helotiales sp., were detected on the roots of willow and birch growing in saline soils (Hrynkiewicz et al., 2015), suggesting their importance in tolerance of host-plants to salinity. Yet, the mechanism by which mycorrhizal fungi improve salt resistance remains unclear. Positive effects of Glomus spp. on olive tree production and growth were confirmed by different studies (Khabou et al., 2014;
Mechri et al., 2014). The cultivation range of this tree crop can be limited by water scarcity as well as ubiquitous gypsum in the soil, which is responsible for osmotic stress and the ionspecific toxicity for plants (Khabou et al., 2014). A number of studies have revealed that mycorrhizal symbiosis is important for improving plant growth and nutrient uptake under saline conditions, especially the uptake of immobile soil nutrients as $\mathrm{P}, \mathrm{Cu}$, and $\mathrm{Zn}$ (Berruti et al., 2015). Inoculation of olive plants with Glomus spp. improves growth and adaptation to arid areas, although AMF colonization did not improve tolerance to Verticillium wilt, one of the most important biotic constraints affecting olive cultivation (see below), under such conditions (Kapulnik et al., 2010).

\section{Endophytes and Diazotrophic Bacteria}

Beneficial endophytes, i.e., any microbe (mainly bacteria and fungi) isolated from asymptomatic plant tissue (Hardoim et al., 2015; Brader et al., 2017) represent another taxonomically and functionally highly diverse group of microorganisms associated with tree crops. Endophytes can promote plant fitness and growth through phytohormones synthesis, nitrogen fixation, phosphate solubilization, synthesis of siderophores or reduction of ethylene levels. Some endophytes can produce active substances with biotechnological potential such as antitumor and antifungal agents (Bhore et al., 2013; Mercado-Blanco and Lugtenberg, 2014; Hardoim et al., 2015). Endophytes of tree crops can also improve the host resistance to external stresses such as contaminants, temperature extremes, water and nutrient limitations, salt, and pathogens (Mei and Flinn, 2010). Thus, it has been demonstrated that some bacterial endophytes of poplar trees can show high tolerance to trichloroethylene (TCE) and potential for degradation of these toxic compounds, e.g., Methylobacterium populum BJ001 (Van Aken et al., 2004), Pseudomonas putida W619-TCE (Weyens et al., 2010), or 
Enterobacter sp. PDN3 (Kang et al., 2012). Endophytic bacteria of willows from the phylum Proteobacteria, particularly the Gammaproteobacteria, increase considerably with cumulative contamination of soils with petroleum hydrocarbon (PHC) (Tardif et al., 2016). Finally, Proteo- and Actinobacteria from the root endosphere and from the rhizosphere of Acer pseudoplatanus L. show detoxifying ability in Trinitrotoluene (TNT)-contaminated soils (Thijs et al., 2014).

Diazotrophic bacteria $\left(\mathrm{N}_{2}\right.$-fixing bacteria) are ubiquitous in the rhizosphere or inside plant tissues of both herbaceous plants and tree crops, serving as significant sources of biologically available nitrogen for them (Bagwell et al., 2001; Kandel et al., 2015). The presence of diazotrophic bacteria in plant tissues of poplar, P. trichocarpa (Torr. \& A.Gray ex Hook.) Brayshaw, and willow, S. sitchensis Sanson ex Bong., including species of Burkholderia, Rahnella, Sphingomonas, and Acinetobacter, was reported by Doty et al. (2009). Experiments confirmed that inoculation of poplar with diazotrophic bacteria increases the biomass over uninoculated control plants and the growth promotion is more pronounced with multi-strain consortia than with single-strain inocula (Knoth et al., 2014). The presence of these diazotrophic microorganisms may help to explain the ability of these tree crops to grow under nitrogen limitation.

Certain trees and woody shrubs from the orders Fagales (e.g., elder, Sambucus sp., from Betulaceae, and beefwood, Grevillea striata R.Br., from Casuarinaceae), Rosales and Cucurbitales are known as "actinorhizal plants," developing endosymbiotic relationships with filamentous, Gram-positive soil bacteria from the genus Frankia (Frankiaceae, Actinobacteria). These bacteria can fix nitrogen $\left(\mathrm{N}_{2}\right)$ both in their free-living form and as symbionts, that is, as beneficial endophytes in root nodules developed on their host plants (Santi et al., 2013), and many actinorhizal plants form mycorrhizal associations. The host plant-Frankia-mycorrhiza symbiotic interaction makes these trees and shrubs capable of adapting to flooded land, arid regions, contaminated soils, extreme $\mathrm{pH}$ and high salinity. They can, therefore, be used for revegetation of different landscapes or for preventing desertification (Dawson, 2008; Santi et al., 2013). For example, actinorhizal plants from Casuarinaceae (e.g., Casuarina equisetifolia) have been successfully used in African coastal and desert dunes for reclamation of salt-affected soils (Diem and Dommergues, 1990).

\section{Nematodes}

Soil nematodes have a number of beneficial and harmful associations with tree-crops, including trophic groups which provide fundamental services in the rhizosphere. Bacteriovorous species play a key role in recycling nutrients and in the dispersal of a number of bacterial groups, including rhizobia. Some bacteriovores in Diplogasteridae may also feed on insects, whereas some Rhabditidae evolved a specialized trophism, feeding on endosymbiotic bacteria that they inoculate on insect larvae, subsequently killed by the induced sepsis. EPN and associated insect-killing bacteria are involved in the natural regulation of many insect pests. Their practical and commercial exploitation as biological control agents (BCA) has been successfully achieved in many agroecosystems, including Citrus and other tree crops (Lewis et al., 2015; Stock, 2015). Most important associations involve two phylogenetically distant $\gamma$-Proteobacteria, Xenorhabdus, and Photorhabdus, that evolved a close necromenic and mutualistic association with two EPN genera, Steinernema and Heterorhabditis, respectively.

Some examples of metabolic or endosymbiotic interactions favoring trees are also available for plant-parasitic nematodes. Pochonia chlamydosporia (Figure 4) is a widespread hyphomycete found in soil as a facultative parasite of eggs of sedentary cyst and root-knot nematodes with a potential as a BCA. Isolates of this fungus showed different levels of adaptation to a wide range of nematode hosts, and in the ability to colonize the rhizosphere or act as root endophytes (Manzanilla-López et al., 2013). In fact, the egg parasitism seems to be correlated with $P$. chlamydosporia host preference, plant compatibility, and tolerance to abiotic factors (Vieira dos Santos et al., 2014). Pochonia chlamydosporia has an intimate metabolic link with roots (Rosso et al., 2014) and the potential of a P. chlamydosporia isolate combined with benzothiadiazole or cis-jasmonate against M. incognita has already been demonstrated (Vieira dos Santos et al., 2013). Studies on eggs degradation and root interactions showed changes of the fungus gene expression levels, in the transition from saprotrophic to the parasitic stage, affecting several metabolic functions. Genes activated after contact with eggs included a bZIP and a phytase-like gene. Sources of P such as phytic acid stimulated the fungal growth. Assays at varying levels of $\mathrm{pH}$ or glucose and $\mathrm{NH}_{4}^{+}$also showed early changes in the fungus metabolism (Rosso et al., 2011, 2014).

Data indicate that $P$. chlamydosporia plays a role in plant nutrition. Both nematode parasitism and nutrient mobilization are indicative of multiple potential benefits related to this fungus. Gene expression data on colonized barley, Hordeum vulgare L., revealed the production of many enzymes such as proteases, hydrolases and carbohydrate esterases (Larriba et al., 2014), suggesting a multilateral relationship with roots and nematodes. Considering the phylogenetic proximity of $P$. chlamydosporia to Metarhizium spp. (Larriba et al., 2014), with the ecology and metabolism of the latter species, some similarities may be inferred. In its endophytic phase, Metarhizium spp. provide to the plant nutrients subtracted by insects feeding on roots, when they are acting as entomopathogens, as shown using radiolabeled compounds (Behie et al., 2012). Although a similar behavior has not yet been demonstrated in P. chlamydosporia, it seems plausible that endophytism and parasitism may be part of a complex behavior, involving the transport of nutrients back to nematode-damaged roots. Further studies are needed to elucidate these patterns. In spite of the widespread occurrence of $P$. chlamydosporia in the rhizosphere of many perennial crops, no information exists on its role in the soil microbiota, either under controlled or field conditions. These studies would require long-lasting experiments on the changes in soil metagenome or root transcriptome, an effort not yet afforded. 

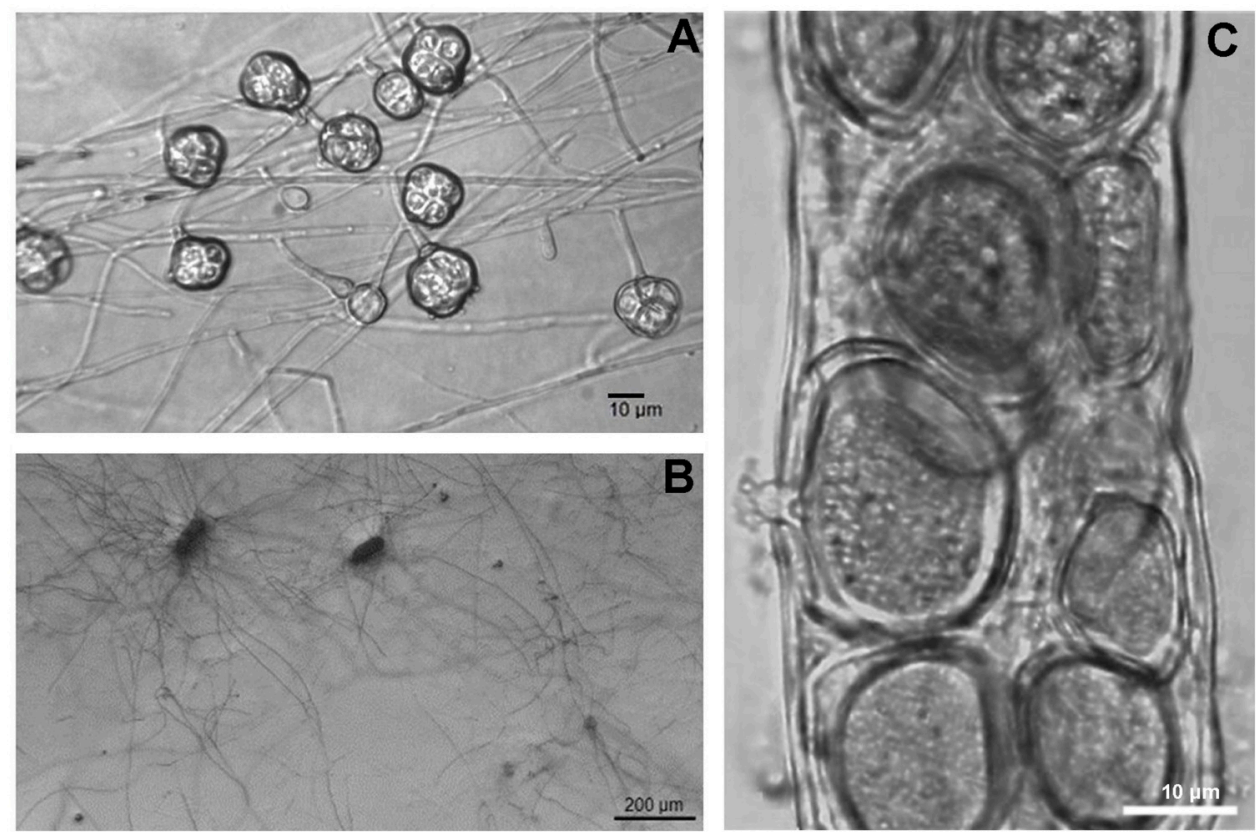

FIGURE 4 | Chlamydospores of the nematode parasitic and root endophytic hyphomycete Pochonia chlamydosporia showing their persistent cellular structure (A). Hyphae emerging from killed root-knot nematode eggs, in vitro (B). The aquatic fungus Catenaria anguillulae (C) is one of the most common parasites of nematodes (in the picture inside Xiphinema sp.) killing its hosts in a few hours. However, in spite of its ubiquity and polyphagy, and due to the zoospores dependence on water for host attachment, a persistent regulation of phytoparasitic nematodes is seldom observed.

\section{Negative Effects}

Although the belowground microbiota is crucial for the health of fruit, nut and SRF crops and timber trees, some members of soil microbial communities present in these agro-ecosystems have negative effects on their hosts (Table 2). On the one hand, the soil may contain inoculum sources of aboveground plant pathogens. On the other hand, the soil/rhizosphere microbiota also harbors a range of soil-borne plant pathogenic agents. Besides the prokaryotes Rhizobium radiobacter and R. rhizogenes (Rhizobiaceae, Rhizobiales, Proteobacteria, formerly known as Agrobacterium tumefaciens and A. rhizogenes, respectively) capable of inducing tumor formation in many economically relevant tree crops (Hwang et al., 2015), the most important negative effectors of tree health in the soil microbiota are fungus-like organisms (i.e., oomycetes) and higher fungi. A brief overview of the most relevant is presented below.

\section{Harmful Oomycetes}

Phytophthora spp. are fungus-like microorganisms belonging to the Pythiaceae family of Peronosporales (Oomycetes, Heterokontophyta, Chromalveolata) and can reproduce both asexually by chlamydospores, or flagellated zoospores moving in soil water, and sexually in the form of oospores (Erwin et al., 1983). Most of the Phytophthora species are considered soilborne pathogens, and several representatives of the genus are known to cause devastating economic losses to various tree crops worldwide (Supplementary Table 1). Phytophthora species also cause significant damage in nurseries and can be spread from infested nursery stocks into tree plantations and forests (Jung and Burgess, 2009). Phytophthora spp. are known to cause various diseases (e.g., root and collar rot, stem canker, branch and foliar dieback) in natural and planted forests (pine, larch, Larix spp. Philip Miller, cypress, family Cupressaceae, oak, Quercus spp., beech, alder, etc.), fruit and nut crops including avocado, Persea americana Mill., apple, pineapple, Ananas comosus (L.) Merr., peach, citrus, cocoa, Theobroma cacao L., almond, Prunus dulcis (Mill.) D.A. Webb, pomegranate, Punica granatum L., fig, Ficus carica L., pistachio, Pistacia vera L., and cinnamon, Cinnamomum verum J. Presl (Supplementary Table 1). Species like Ph. alni, Ph. lateralis or Ph. quercina are more specialized, while others (e.g., Ph. cinnamomi, Ph. niederhauserii, $P h$. palmivora, or Ph. plurivora) display a wide host range.

The genus Pythium from the Pythiaceae family, commonly occurring in forest nursery soils, also harbors important soilborne pathogens causing damping off of tree seedlings and root rot of mature trees. The life cycle of Pythium species is similar to that of Phytophthora. A study conducted on seedlings of Douglas-fir, Pseudotsuga menziesii (Mirb.) Franco, demonstrated that besides $P y$. aphanidermatum, $P y$. irregulare, Py. debaryanum, Py. sylvaticum, and Py. ultimum, the species Py. mamillatum can also cause seedling dampingoff, while others, e.g., Py. dissotocum, Py. aff. macrosporum, $P y$. aff. oopapillum, $P y$. rostratifingens, may be responsible for seedling loss (Weiland et al., 2013). Pythium ultimum and Py. aphanidermatum were also known to infect seedlings of tropical tree species (Augspurger and Wilkinson, 2007). The species 
TABLE 2 | Examples for the most relevant microorganisms affecting tree crops as soil-borne pathogens.

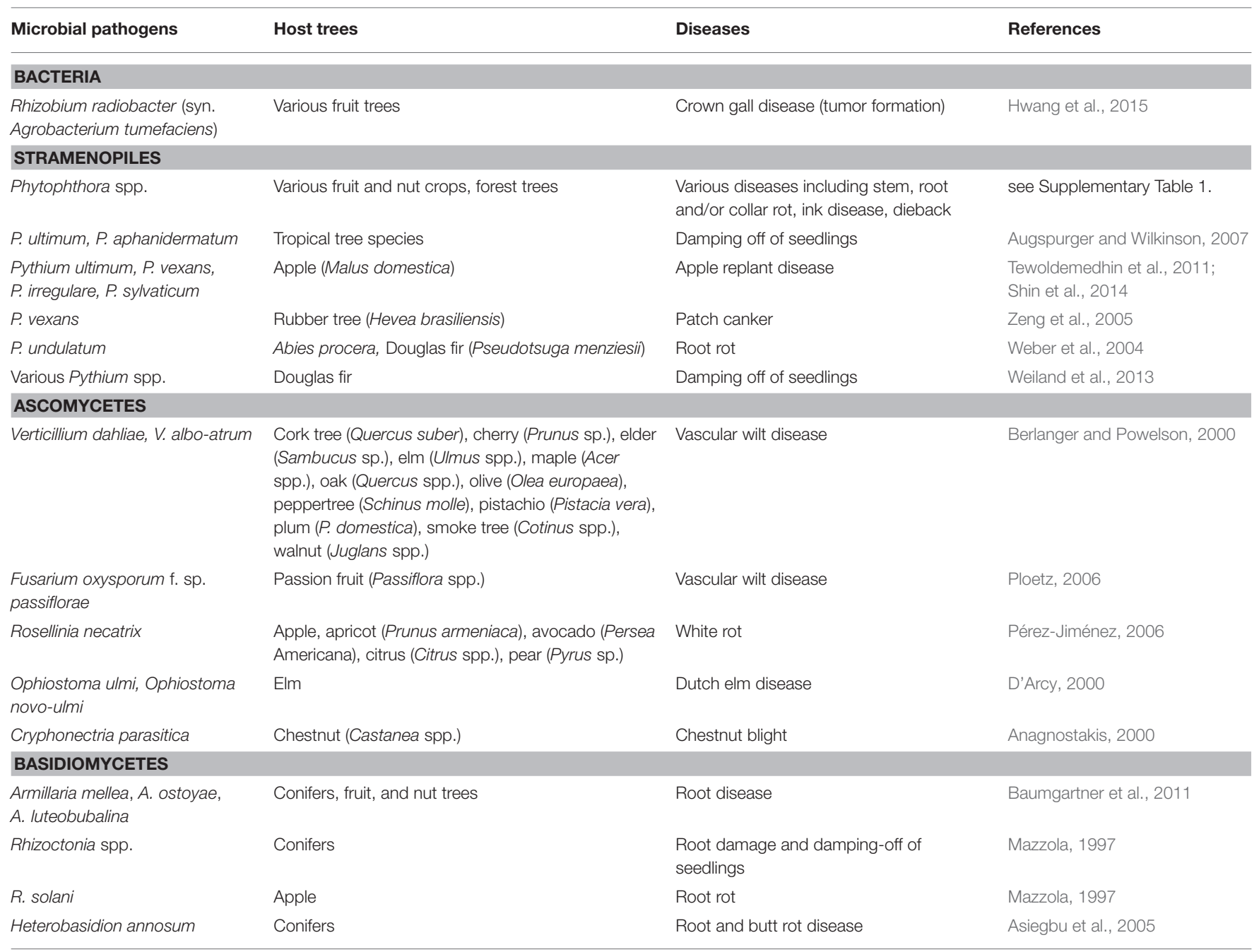

Py. ultimum, Py. vexans, Py. irregulare and Py. sylvaticum are associated with the worldwide occurring apple replant disease complex (Tewoldemedhin et al., 2011; Shin et al., 2014). Pythium vexans is a pathogen of rubber tree (Hevea brasiliensis Muell. Arg.) (Zeng et al., 2005), while Py. undulatum was identified as the causal agent of a devastating root rot disease of the Christmas tree Abies procera Rehd and Douglas fir [Pseudotsuga menziesii (Mirbel) Franco] in Northern Germany (Weber et al., 2004).

\section{Deleterious Fungi Affecting Tree Crops}

Among the higher fungi, important soilborne tree pathogens can be found both in Ascomycota and Basidiomycota. The most important ascomycetous soilborne pathogens causing wilt diseases of tree crops belong to the genera Verticillium and Fusarium. The economically most relevant member of the genus Verticillium (Plectosphaerellaceae, incertae sedis, Ascomycota) causing wilt diseases in tree crops is $V$. dahliae (Hiemstra and Harris, 1998; Berlanger and Powelson, 2000). Microsclerotia ensure the persistence of the fungus in soils for many years without susceptible hosts. In their presence, microsclerotia germinate in response to root exudates and the germinating hyphae penetrate the root, colonize the cortex and enter the xylem vessels, where the fungus is spread further by conidia (Pegg and Brady, 2002). Among many others, susceptible tree hosts of $V$. dahliae include elm, Ulmus spp., cork tree, Quercus suber L., elder, maple, Acer spp., oak, pepper tree, Schinus molle L., olive, smoke tree, Cotinus spp., cherry, plum, pistachio and walnut, Juglans spp. (Hiemstra and Harris, 1998).

Fusarium wilt is a vascular disease similar to Verticillium wilt. The disease is caused by members of the F. oxysporum species complex (FOSC, Nectriaceae, Hypocreales, Ascomycota), producing macro- and microconidia and chlamydospores allowing survival in the soil and plant debris. For instance, F. oxysporum f. sp. passiflorae causes wilt disease in passion fruit, Passiflora edulis Sims (Ploetz, 2006). Further important ascomycetous pathogens of trees include Rosellinia necatrix (Xylariaceae, Xylariales) causing white rot in several hosts including apples, apricots, avocados, pears and citruses (Pérez-Jiménez, 2006), Ophiostoma ulmi and 
O. novo-ulmi (Ophiostomataceae, Ophiostomatales), the causal agents of the Dutch elm disease (D'Arcy, 2000) and Cryphonectria parasitica (Cryphonectriaceae, Diaporthales) causing the blight of chestnut, Castanea spp. (Anagnostakis, 2000).

Concerning the basidiomycete fungi, the most relevant soil-borne tree pathogens from an economical point of view are the honey mushrooms from the genus Armillaria (Physalacriaceae, Agaricales, Basidiomycota), causing root diseases in fruit trees (e.g., Citrus, Malus and Prunus species), nut crops (e.g., Juglans spp.) and timber trees (e.g., Abies, Picea, Pinus, and Pseudotsuga spp.) in both hemispheres of the world under temperate, boreal and tropical climates (Baumgartner et al., 2011). The most virulent species are $A$. mellea, A. ostoyae, and A. luteobubalina. Mycelia of Armillaria species are able to survive for several years in woody residual roots even after the removal of infected trees, which serve as inoculum for the infection of the next crop. During their infection cycle, Armillaria species can grow in contact with the host in the form of rhizomorphs - root-like multicellular structures of clonal dispersal enabling the achievement of immense colony sizes (Sipos et al., 2017)- which employ a combination of mechanical force and extracellular enzymes to penetrate root bark (Baumgartner et al., 2011). The mycelium is then colonizing the cambium of the living roots, killing the root tissues and utilizing them for nutrition. The fungus forms white, thick mats of mycelia beneath the bark of infected roots. Further symptoms of the diseased plants include dwarfed foliage, wilting, premature defoliation and stunted shoots in the case of conifer hosts, while dwarfed fruits can be observed in the case of fruit and nut crops. After the death of the host, Armillaria switches from parasitic to saprophytic phase and persists in the rhizosphere as a white-rotting fungus (Baumgartner et al., 2011). Rhizoctonia species (Ceratobasidiaceae, Cantharellales, Basidiomycota) are worldwide-distributed soil fungi with the capability to produce sclerotia overwintering in the soil. Members of this genus bear significant plant pathogenic potential and a wide host range including conifers, where the fungus may cause root damage and damping-off of seedlings (Hietala and Sen, 1996). Rhizoctonia solani is known to cause root rot in apple orchards (Mazzola, 1997). Relevant soil-borne basidiomycetous tree pathogens also include Heterobasidion annosum (Bondarzewiaceae, Russulales) causing root and butt rot disease of conifers (Asiegbu et al., 2005).

\section{HARNESSING BENEFICIAL COMPONENTS OF BELOWGROUND MICROBIOTA TO SUSTAIN TREE CROPS}

The soil targets for protection of tree crop plantations by means of biocontrol approaches include bacterial and fungal pathogens, nematodes and insect larvae (Cazorla and MercadoBlanco, 2016). Root and rhizosphere microbiota of healthy fruit, nut, and timber trees are rich and powerful sources of BCA (Aranda et al., 2011). Below we present an overview of representative examples of BCA used against relevant biotic constraints of tree crops. Regarding biocontrol approaches implemented against soil-borne pathogenic bacteria infecting trees, the success of the non-pathogenic $R$. radiobacter strain K84 (formerly known as Agrobacterium radiobacter K84) to control crown gall caused by pathogenic $R$. radiobacter strains (formerly known as A. tumefaciens) in different agroecosystems worldwide has been impressive. Interested readers can consult, for instance, the reviews by Moore (1988) and Kerr (2016).

\section{Biocontrol-Based Tools Against Deleterious Oomycetes}

Due to the substantial economic damage caused by funguslike organisms, there is an emerging need for large-scale screening efforts and the development of biocontrol strategies against oomycete tree pathogens. Among prokaryotes, the most promizing taxa with potential as BCA of oomycetes are within the genus Pseudomonas (Gammaproteobacteria, Pseudomonadales, Pseudomonadaceae) (Mercado-Blanco, 2015) and the order Bacillales (Firmicutes) (Borriss, 2015). Examples of bacteriabased biocontrol of woody crop diseases caused by Phytophthora spp. include field studies performed in citrus orchards against $P h$. parasitica using $P$. putida 06909, a biocontrol strain capable of actively colonizing the hyphae of Phytophthora spp. (Steddom et al., 2002). Acebo and colleagues isolated 127 rhizobacteria from the rhizosphere of cocoa, identifying three strains of $P$. chlororaphis with both in vitro and direct antagonistic potential against the black pod rot pathogen $P h$. palmivora. The biosurfactant viscosin was found to be crucial for the motility and biofilm formation of $P$. chlororaphis. Even though the involvement of viscosin in antagonism against Phytophthora was not demonstrated, its possible role in the bioprotection of T. cacao was suggested (Acebo-Guerrero et al., 2015). The ability of Bacillus amyloliquefaciens (Firmicutes, Bacillales, Bacillaceae) strain HK34 to induce systemic resistance in ginseng to $P h$. cactorum suggests that this species may have potential also in the management of other tree diseases caused by the same pathogen (Lee et al., 2015).

Besides bacteria, the ascomycete Trichoderma (Hypocreales, Hypocreaceae) is also a powerful source of potential BCA against oomycete tree pathogens. Thus, the mycoparasitic activity of T. virens was shown to be involved in the control of Pythium. ultimum (Djonović et al., 2006), while the antagonistic potential of strains T. virens T7, T. harzianum T40, T. asperellum T54 and T. spirale T4 was demonstrated against $P h$. palmivora (Mpika et al., 2009). Trichoderma saturnisporum was recently found to improve plant quality and showed biocontrol activity against Phytophthora spp., including Ph. parasitica (Diánez Martínez et al., 2016).

\section{Biological Control of Soil-Borne Phytopathogenic Fungi Causing Vascular Diseases}

Soil-borne fungi causing vascular diseases are also important threats to plants, including woody hosts. Pathogenic 
representatives of Verticillium spp. pose a serious risk in many agro-ecosystems worldwide (Pegg and Brady, 2002; Inderbitzin et al., 2011). Verticillium wilts are among the most threatening biotic constraints for tree crops in many areas (Hiemstra and Harris, 1998). Biological control exerted by soil-borne beneficial microorganisms can be useful to confront the disease, particularly when applied as a preventive measure (Mercado-Blanco et al., 2004). One of the best examples in which effective BCA have been identified, characterized and successfully used is the case of Verticillium wilt of olive (VWO) caused by V. dahliae Kleb (López-Escudero and Mercado-Blanco, 2011). Strains of Pseudomonas spp. have been isolated from the olive rhizosphere (and elsewhere), and proved to suppress VWO in young, nursery-produced plants (Mercado-Blanco et al., 2004; Sanei and Razavi, 2011; Triki et al., 2012; Gómez-Lama Cabanás et al., 2018). One of the best known BCA against VWO is $P$. fluorescens PICF7 (Prieto et al., 2009; Martínez-García et al., 2015). This strain is a natural inhabitant of the olive rhizosphere and endophytically colonizes olive root tissues (Prieto and Mercado-Blanco, 2008; Prieto et al., 2011). While our knowledge about the traits of strain PICF7 involved in both endophytism and biocontrol is scarce (Maldonado-González et al., 2015), results have shown that olive root colonization by this bacterium triggers broad transcriptomic changes, both at local (roots) and systemic (aboveground tissues) level (Schilirò et al., 2012; Gómez-Lama Cabanás et al., 2017). Many of these changes are related to defense responses to different (a)biotic stresses and may shed light on why this endophyte is recognized by the host as a non-hostile colonizer and provide clues on the underlying mechanisms of its biocontrol activity. However, while aboveground defense responses are induced upon strain PICF7 root colonization, they are not effective to control another relevant olive pathogen, Pseudomonas savastanoi pv. savastanoi causing olive knot disease (Maldonado-González et al., 2013). Furthermore, where and when strain PICF7 is applied in the olive root system seems to be crucial for the effective suppression of VWO (Gómez-Lama Cabanás et al., 2017). Other soil-borne microorganisms have been studied and used as effective antagonists and/or BCA against $V$. dahliae, such as the bacteria Serratia plymuthica HRO-C48 (Müller et al., 2007) and Paenibacillus alvei K165 (Markakis et al., 2016), or the fungi T. harzianum CECT 2413 (Ruano-Rosa et al., 2016) and T. asperellum T25 and Bt3 (Carrero-Carrón et al., 2016). The report by Markakis et al. (2016) demonstrated for the first time an effective biocontrol of VWO under field conditions, a scenario not frequently explored in biocontrol research, particularly with trees (Cazorla and Mercado-Blanco, 2016). A recent review highlights all desirable traits that a BCA should have to confront pathogenic Verticillium spp., including those ones affecting tree crops. Similar requisites can likely be taken into account, when considering other soil-borne fungal phytopathogens (Deketelaere et al., 2017).

Additional prominent examples of biological control of tree pathogenic ascomycetes are the application of $V$. albo-atrum for the control of Dutch elm disease caused by O. ulmi and O. novoulmi (Scheffer et al., 2008; Postma and Goossen-van de Geijn, 2016), the exploitation of the hypovirulence phenomenon in the case of a dsRNA mycovirus-harboring strain of C. parasitica against chestnut blight (Milgroom and Cortesi, 2004) or the possibility of using fungi (Trichoderma species) or bacteria ( $P$. fluorescens, Bacillus subtilis) for the control of avocado white root rot caused by $R$. necatrix (Sztejnberg et al., 1987; Cazorla et al., 2006, 2007; Ruano-Rosa and López Herrera, 2009).

\section{Biological Control of Other Phytopathogenic Fungi}

Amongst the soilborne basidiomycete pathogens of fruit and nut crops and timber trees, the main targets of biocontrol efforts are members of the genus Armillaria. BCA of Armillaria act through the limitation of the pathogen to-or elimination fromthe already occupied substrate, and prevention of rhizomorph and mycelium development (Fox, 2003). Potential Armillaria antagonists include Trichoderma species: scanning electron microscopy studies revealed that some Trichoderma strains are able to attack and penetrate the outer tissue of the rhizomorphs, killing Armillaria hyphae after coiling and direct penetration (Dumas and Boyonoski, 1992; Pellegrini et al., 2012). Other fungi antagonistic to Armillaria include Rhizoctonia lamellifera that prevents the pathogen from colonizing tea roots, Scytalidium lignicola and its toxin scytalidin inhibiting Armillaria growth in vitro, Phlebiopsis gigantea and Pleurotus ostreatus capable of excluding Armillaria from its substrates, Coriolus versicolor, Stereum hirsutum, and Xylaria hypoxylon reducing the stump colonization by Armillaria, and cord-forming saprotrophs acting as competitive antagonists (Fox, 2003). The method based on isotope ratio mass spectrometry developed to study trophic interactions between A. mellea and fungal/bacterial antagonists is a promizing tool for the screening of further potential BCA (Pellegrini et al., 2012). Further examples for the biological control of tree pathogenic basidiomycetes are the application of forest soil-derived Streptomyces spp. or $P$. gigantea (Basidiomycota, Polyporales, Phanerochaetaceae) to control $H$. annosum causing root and bud rot of conifers (Lehr et al., 2008; Sun et al., 2009).

\section{Biological Control Strategies Against Nematode and Insect Pests}

Some specific and effective nematode antagonists such as Pasteuria spp. have been reported on tree crops, and their regulatory role described as well (Ciancio, 1995; Ciancio et al., 2016). As concerns the role of bacteria in nematode and insect management (see below), it is worth mentioning that our knowledge about several lineages is still very limited (Roesch et al., 2007).

In most cases, nematodes play different roles in soil food webs, acting as preys, predators, saprotrophs, or feeding on bacteria, fungi, roots or other invertebrates (Figure 2). Their association with tree roots and endoparasites, such as Pasteuria spp., can be monitored through the collection of time series data on host density and prevalence. Pasteuria spp. have a very narrow host specificity, due to an obligate parasitic behavior. Their persistence in soil is due to the presence of durable endospores, which are also the infective propagules. Through 
this strategy these bacteria reduce their competition with other soil bacteria, confining their vegetative growth in the small microhabitat provided by the nematode body. This food web can persist for 20 years, as experimentally shown on a citrus grove in Southern Italy (Ciancio et al., 2016). In a different study on Xiphinema diversicaudatum-peach and Pasteuria sp. carried out in Piedmont, the food web persisted for at least 15 years. The nematode is a virus vector, and its population was also targeted by a predatory nematode (Discolaimus sp.), which in turn hosted a distinct Pasteuria sp. After trees have been removed from the parcel of study, the nematodes and Pasteuria associations were found 20 years later in other adjacent fields, suggesting a local endemism due to soil movement by farmers or water flows, and to the presence of natural reservoirs.

Until the late 1980's, many nematode pests were mostly managed by pesticides or soil fumigants. However, the use of nematicides raised several concerns for their potential harm to farmers, consumers, and damage to the environment (wildlife, water or soil pollution). Attention has thus been given to the effects of biological components of the rhizosphere on nematodes. Bacterial and fungal components of tree rhizosphere microbiota can also be exploited as BCA of phytoparasitic and soil-dwelling nematodes and insect larvae damaging forests and tree plantations. Predation and parasitism arose several times during the evolution of early eukaryotes and may be found among aquatic fungi, ascomycetes, and basidiomycetes. Aquatic fungi such as Catenaria anguillulae or Myzocitium spp. penetrate the nematode cuticle through motile zoospores that adhere to the host. After an encystation stage, colonization of the host body occurs through germinating thalli. While these species have specific parasitic habits and can regulate nematodes in a humid and wet soil environment, their regulatory potential appears, however, limited depending on high soil water content (Singh et al., 2007).

Many hyphomycetes like Arthrobotrys or Drechslerella spp. (Ascomycota, Orbiliaceae) produce hyphal traps or nets that actively capture and/or attract passing nematodes. This character arose through adaptive evolution in two distinct lineages, one trapping through constricting rings and the other by adhesive nets (Yang et al., 2007). Other parasitic strategies developed by hyphomycetes include the direct, passive adhesion of infective conidia to the nematode cuticle, with germinating hyphae penetrating the host to develop a lethal infection. These strategies are found in species such as Hirsutella rhossiliensis (anamorph of Cordiceps sp.), Meria coniospora or Nematoctonus spp., the latter a teleomorph of Hohenbuehelia (Basidiomycota, Agaricales, Pleurotaceae). Nematoctonus also shows the production of toxins by the germinating conidia, which reduce the host movement, thus lowering the probabilities of an early loss of the infective propagule (Giuma and Cooke, 1971). Paecilomyces (Purpureocillium) lilacinus may degrade nematode eggs and regulate their density, due to the activity of several chitinolytic and proteolytic enzymes. The latter provides the fungus a strong keratinolytic activity, a trait supporting its pathogenicity to superior animals, including man.

Pochonia chlamydosporia is also a root endophyte that may elicit several defensive pathways after colonization, without induction of any visible root damage (Maciá-Vicente et al., 2009; Ciancio et al., 2013; Rosso et al., 2014; Larriba et al., 2015). This behavior is indicative of a long-term evolutionary adaptation to the rhizosphere environment, exploiting strategies involving multitrophic relationships with the plants and other rhizosphere organisms.

Finally, pine wilt disease is caused by the pinewood nematode Bursaphelenchus xylophilus, leading to the death of susceptible pine trees. In order to control this disease, a few studies have been performed using chemical or biological compounds (Proença et al., 2017b). Several strains were reported to produce extracellular compounds with nematicidal activity, among which Serratia marcescens A88copa13 that produces an extracellular serine protease as the major key factor toward the nematode (Paiva et al., 2013).

Although most of the insect damage to fruit and nut crops and forest trees can be attributed to their herbivoural defoliating activity, a few of them are also important as soil-borne pests because their larvae feeding on the roots. An example of EPN impact and the regulatory role played in soil food webs is the biocontrol and management of Diaprepes sp. and other rootweevils infesting citrus and other perennial crops in Florida (Campos-Herrera et al., 2013, 2015). Other relevant examples are the larvae of May bugs (also known as white grubs), especially those of the forest cockchafer (Melolontha hippocastani), a species widely distributed in Eurasia. Besides EPN like Steinernematidae and Heterorhabditis spp. (Woreta, 2015), larvae of the forest cockchafer are subjected to infections by entomopathogenic fungi (e.g., Beauveria brongniartii) and bacteria (like Bacillus popilliae var. melolonthae or B. thuringiensis).

In the case of $B$. brongniartii, cereal grains infected with mycelia is the most frequent formulation used for the control of M. hippocastani. However, as summarized by Woreta (2015), the field performance of this biocontrol strategy revealed ambiguous results during several attempts since the 1880s in France, Poland, Italy, Switzerland, and Germany. This situation can be explained by difficulties of introducing and blending infected grains with the soil, especially around young trees where the abundance of cockchafer grubs is expected. Although it was shown that, under field conditions, grub population can be decreased to a harmless level by the application of an adequate B. brongniartii formulation thoroughly mixed with soil and applied at sufficient air temperature and humidity, B. brongniartii has not been authorized in the EU for use in commercial plant protection products (Woreta, 2015).

Among bacteria, B. popilliae var. melolonthae, the causal agent of the milky disease, has also been studied as a potential BCA of cockchafer grubs (Franken et al., 1996). The disease incidence increased when the grubs were infected simultaneously with $B$. popilliae and B. brongniartii, which is possibly due to synergistic effects between the two pathogens, suggesting the possibility of integrated biological control. Highly pathogenic $B$. thuringiensis subsp. tenebrionis and $B$. weihenstephanensis strains, isolated from larvae of the common cockchafer M. melolontha (Kati et al., 2007; Sezen et al., 2007), or Serratia species, causing feeding discontinuation of M. hippocastani larvae (Jackson and Zimmermann, 1996), may 
be valuable as BCA of cockchafer white grubs damaging tree roots.

\section{Inconsistencies and Risk Assessment in Biological Control of Tree Crops}

Inconsistent field performance is one of the major challenges in the application of beneficial microorganisms as BCA and/or plant growth promoters (Weller et al., 1995). It is even more complex in the case of trees because of their own idiosincracy (Cazorla and Mercado-Blanco, 2016). Inconsistency can be the result of various abiotic and biotic factors (Meyer and Roberts, 2002). Physicochemical properties of the rhizosphere (temperature, $\mathrm{pH}$, water availability, chemical composition) are parameters varying both in space and time, which have substantial influence on the performance of plant growth promoting and biocontrol microorganisms: an individual agent can have different activities in different soil environments. One of the possible approaches to counteract inconsistencies under different environmental conditions is the development of strategies based on more than just a single beneficial organism. The combined application of wide-spectrum BCA with efficient plant growth promoting microorganisms has the potential to reach the increased consistency of performance over a wider range of soil conditions. A recent example was presented by Imperiali et al. (2017), who applied Pseudomonas bacteria, AM fungi and EPN to improve wheat performance. Moreover, the application of entire, well-characterized, complex microbiota may further improve the efficiency of soil-borne pathogen management and other biotic constraints (Gopal et al., 2013; Berg et al., 2014; Kowalski et al., 2015). Other examples are the effect of chemically and microbiologically characterized vegetable compost in oak seedlings on decline caused by Ph. cinnamomi (Moreira et al., 2010), and the efficiency of organic amendments (yard waste and almond shells) to avocado crops in suppression of the white root rot fungus, $R$. necatrix (Bonilla et al., 2015). Based on their results these authors suggested that organic amendments can be useful cultural practices to reduce the impact of the pathogens.

Although sophisticated and ecologically "intelligent", many fungi acting as predators or parasites show a reduced biocontrol efficacy for pests such as root-knot (Meloidogyne spp.), cyst (Heterodera spp., Globodera spp.) or other nematode species, once applied to soil as bioformulations (Jaffee, 1992; Kluepfel et al., 2002; Castillo et al., 2010). The reasons for such low performance may depend on several factors, including the inhibition by the resident soil microflora, the evolution of low virulence traits allowing the maintenance of the host population, or the capacity of most fungi to grow on a wide range of substrates, using nematodes as additional food sources. Other factors are related to density-dependent relationships established with their hosts, as shown for $H$. rhossiliensis on M. xenoplax on peach or for other fungi parasitic on nematode eggs on kiwi (Jaffee et al., 1989; Roccuzzo et al., 1993). A further factor concerns the evolution of more complex adaptative behaviors, as in the case of the egg parasite $P$. chlamydosporia (Figure 4). This parasite produces specific enzymes allowing the lysis of the egg cuticle and vitelline layers, a step followed by the egg colonization through an appressorium and growing hyphae. This fungus has been reported as a highly-effective BCA, displaying specificity for the nematode species from which the isolates were obtained (Manzanilla-López et al., 2013).

Lastly, when planning the application of a biocontrol strategy, a thoroughly performed risk assessment is necessary. The EU policy support action REBECA (Regulation of Biological Control Agents) aims to review the possible risks of biocontrol agents (http://www.rebeca-net.de/?p=999). BCA may have negative effects on beneficial, non-target organisms (e.g. mycorrhizal fungi) or other crops. For example, although many Trichoderma species are considered as potential BCA for the protection of both herbaceous and woody plants, certain members of the genus, e.g., T. aggressivum,T. pleurotum and T. pleuroti, represent a risk to commercial mushroom production where they can cause green mold disease (Hatvani et al., 2008; Kredics et al., 2010) or to human health, with T. longibrachiatum as a potential opportunistic human pathogen (Hatvani et al., 2013). The application of these Trichoderma species for biocontrol purposes should, therefore, be carefully monitored.

\section{Coping With Abiotic Stresses and Phytoremediation}

Tree crops used in SRF aiming to biomass production (e.g., Salix spp. and Populus spp. and their hybrids) have been successfully used as sustainable solutions to recover contaminated soil (Licht and Isebrands, 2005; Zalesny et al., 2016). Phyto-assisted bioremediation, or phytoremediation, is an in situ treatment of contaminated soils, which relies on complex interactions established between roots and soil microorganisms in the rizhosphere (Wenzel, 2009). In this microhabitat, bacterial communities can respond promptly to pollutant occurrence, promoting organic contaminant degradation and/or inorganic phyto-containment (Simpson et al., 2009). Bioaugmentation of soils with selected microorganisms can significantly increase efficiency of phytoremediation (Złoch et al., 2017). The synergistic action between the tree root system and the natural belowground microbiota makes it possible to remove, convert, or contain toxic substances in soils.

Beyond the contaminant removal, an overall soil quality improvement is observable in terms of soil carbon sequestration, increased nutrient content, recycling and biomass production for energy purposes. Poplar is one of the most used tree crops for stimulating (e.g., through root exudates production, oxygen transport) bacterial degradation of persistent organic contaminants (e.g., polychlorinated biphenyls - PCB) and phytocontainment of inorganic ones (heavy metals) in the rhizosphere (Gamalero et al., 2012; Ancona et al., 2017). However, other tree species have been successfully applied for this purpose such as willow (Salix spp.), eucalyptus, black locust (Robinia pseudoacacia Simpson et al., 2009) and Corylus spp. for metal and metalloid phyto-containment (Radojevic et al., 2017). Although bacteria and archaea are the only groups within the plant microbiota able to transform and mineralize organic 


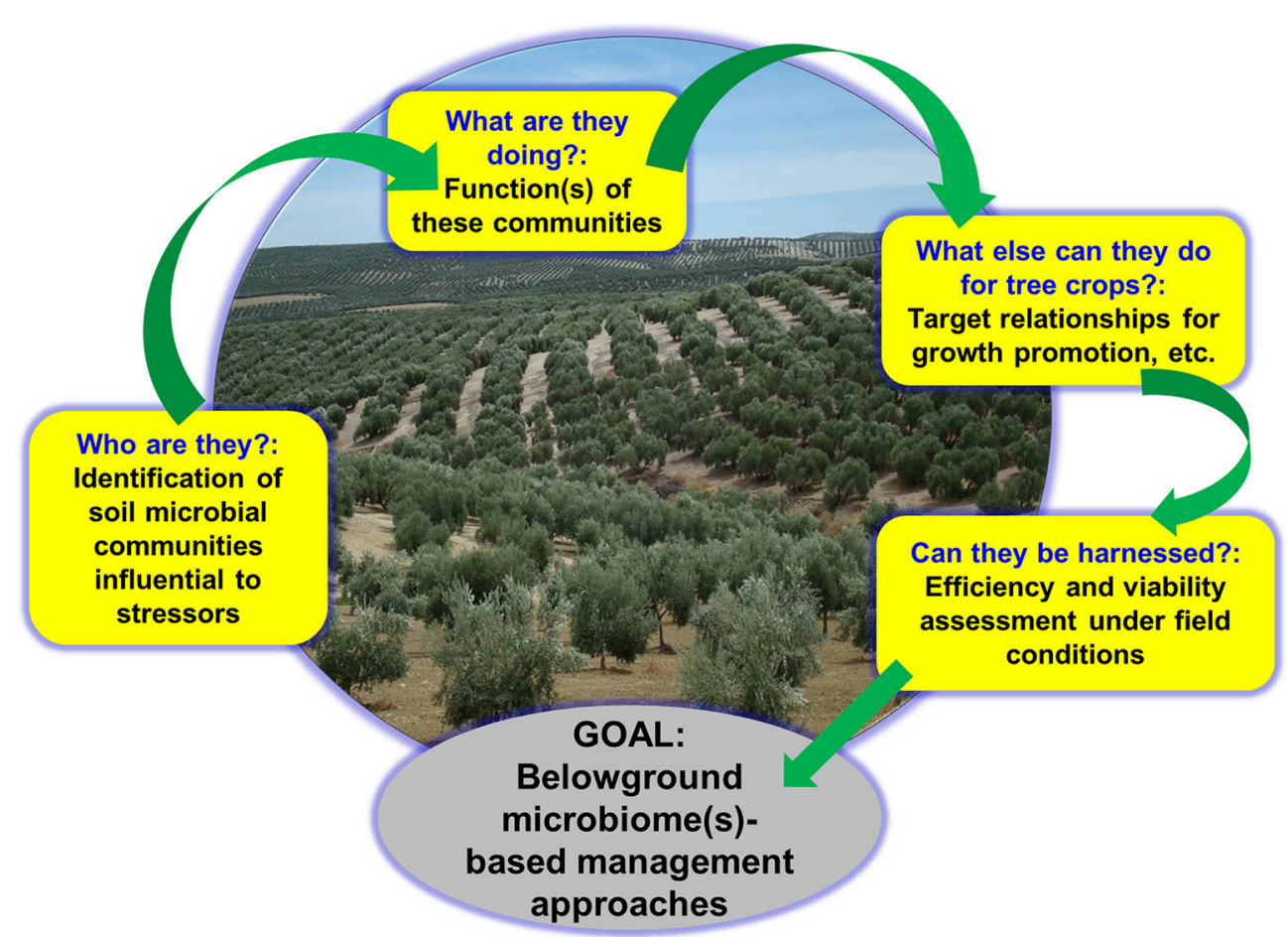

FIGURE 5 | A strategy to manage biotic constraints affecting tree crops (i.e., pathogens, pests, invasive species) based on the identification, characterisation and harnessing of soil/root microbiota [based on a conceptual framework by Kowalski et al. (2015)].

contaminants, their huge metabolic potential remains to be explored.

\section{CONCLUDING REMARKS: TOWARD MICROBIOTA-ASSISTED MANAGEMENT STRATEGIES}

Belowground microbial communities associated with tree crops are key factors for their growth, development, and health, particularly under non-favorable soil conditions. They decisively contribute to enhanced productivity, improve accessibility to low-abundant nutrients, cope with a range of (a)biotic stressors that affect their associated hosts, and also play an important role in phyto-assisted biodegradation of toxic compounds present in soils. Until now, how belowground microbiota contribute to the fitness of tree crop agro-ecosystems, remains largely unknown and only now it is starting to be unraveled in detail. The four fundamental questions to better understand these associations are: who are there? what are they doing? who is active out there? and how do activities of these microorganisms relate to ecosystem functions? (Amann, 2000; Leveau, 2007). The answers to these questions, based on an in-depth knowledge of the structure and functioning of belowground communities, will constitute the pillars to develop holistic management strategies aiming to cope with the range of (a)biotic constraints affecting tree crops (Figure 5). The relationship between soil-borne microbes and tree crops is delicate and complex and can have either positive or negative effects on the host. It can be assumed that benefits derived from the interaction of tree crops with beneficial belowground (micro)organisms are expected to yield similar outcomes in aboveground ecosystems than those observed, and more frequently investigated, in herbaceous, short-living species. Moreover, the associations established with trees are expected to be more stable, enduring along time, although variations in composition, structure, and functioning do occur, likely in a cyclic manner. These are subjected to a broad range of genetic, (a)biotic and environmental cues and factors. In this sense, integrated "omic" analyses, combining metagenomics, metatranscriptomics, metaproteomics, and metabolomics, are now providing a more accurate view of the activities and the physiological potential of belowground plant-associated microbiota (Zhang et al., 2010; Knief, 2014).

Studies on tree crop production and diseases have thus far historically relied on single microbe-based formulations or focused on single species (the pathogen), while little attention has been paid to the use of consortia of beneficial microorganisms or to investigate many other microorganisms most likely present in the infection sites. One way to assist tree crop production might be to integrate beneficial plant microbiota or use ad hoc tailored microbiota to target specific deleterious agents (Gopal et al., 2013; Kowalski et al., 2015; Pinto and Gomes, 2016; Berg et al., 2017; Figure 5). Due to the complexity of tree crop ecosystemsdominated by vegetal species displaying peculiarities such as large biomass, complicated anatomy, large root systems, longevity, and the large spatial domains and timescales over which tree crops are grown -management options such as soil amendments, intercropping and soil processing can be applied by farmers. 
Once again, the currently-available multi-omic tools, combined with other methodological approaches, will provide a much better knowledge on the complex network of trophic interactions taking place at the soil/root level (Massart et al., 2015). A more-in-depth analysis of these interactions could be of crucial importance in designing new and effective microbial consortia for optimizing plant production and developing new strategies for disease control. In conclusion, a more holistic approach to tree crop agriculture is needed. Understanding the microbial diversity, distribution, activity, and function, and linking the microbial community structure with both environmental factors and ecosystem functioning, are major challenges for the soil/plant microbiology science in this century.

\section{AUTHOR CONTRIBUTIONS}

All authors listed have made a substantial, direct and intellectual contribution to the work, wrote the review and gave approval to the final version. JM-B designed the study. AB critically reviewed the manuscript and supervised the manuscript drafting.

\section{FUNDING}

This work was supported by the COST Action FP1305 BioLink: Linking belowground biodiversity and ecosystem function in

\section{REFERENCES}

Acebo-Guerrero, Y., Hernández-Rodríguez, A., Vandeputte, O., Miguélez-Sierra, Y., Heydrich-Pérez, M., Ye, L., et al. (2015). Characterization of Pseudomonas chlororaphis from Theobroma cacao L. rhizosphere with antagonistic activity against Phytophthora palmivora (Butler). J. Appl. Microbiol. 119, 1112-1126. doi: $10.1111 /$ jam. 12910

Ali, J. G., Alborn, H. T., and Stelinski, L. L. (2010). Subterranean herbivoreinduced volatiles released by citrus roots upon feeding by Diaprepes abbreviatus recruit entomopathogenic nematodes. J. Chem. Ecol. 36, 361-368. doi: $10.1007 / \mathrm{s} 10886-010-9773-7$

Ali, J. G., Alborn, H. T., and Stelinski, L. L. (2011). Constitutive and induced subterranean plant volatiles attract both entomopathogenic and plant parasitic nematodes. J. Ecol. 99, 26-35. doi: 10.1111/j.1365-2745.2010. 01758.x

Ali, J. G., Campos-Herrera, R., Alborn, H. T., Duncan, L. W., and Stelinski, L. L. (2013). Sending mixed messages: a trophic cascade produced by a belowground herbivore-induced cue. J. Chem. Ecol. 39, 1140-1147. doi: 10.1007/s10886-013-0332-x

Al-Karaki, G. N. (2013). "The role of mycorrhiza in the reclamation of degraded lands in arid environments," in Developments in Soil Classification, Land Use Planning and Policy Implications: Innovative Thinking of Soil Inventory for Land Use Planning and Management of Land Resources, eds S. A Shahid, F. K Taha, and M. A. Abdelfattah (Dordrecht: Springer), 823-836.

Allen, M. F. (2006). "Water dynamics of mycorrhizas in arid soils," in Fungi in Biogeochemical Cycles, ed G. M. Gadd (Cambridge, UK: Cambridge University Press), 74-97.

Allison, S. D., and Vitousek, P. M. (2005). Responses of extracellular enzymes to simple and complex nutrient inputs. Soil Biol. Biochem. 37, 937-944. doi: 10.1016/j.soilbio.2004.09.014

Amann, R. (2000). Who is out there? Microbial aspects of biodiversity. Syst. Appl. Microbiol. 23, 1-8. doi: 10.1016/S0723-2020(00)80039-9

Anagnostakis, S. L. (2000). Revitalization of the majestic chestnut: chestnut blight disease. APSnet Featur. doi: 10.1094/APSnetFeature-2000-1200
European forests (http://www.bio-link.eu). JM-B is supported by grants AGL2016-75729-C2-1-R from the Spanish Ministerio de Economía, Industria y Competitividad/Agencia Estatal de Investigación and P12-AGR-0667 from Junta de Andalucía, both co-financed by the European Regional Development Fund (ERDF). LK was supported by grant GINOP-2.3.2-15-201600052 (Széchenyi 2020 Programme) and the János Bolyai Research Scholarship (Hungarian Academy of Sciences). DNP was supported by Fundação para a Ciência e a Tecnologia, postdoctoral fellowship SFRH/BPD/100721/2014.

\section{ACKNOWLEDGMENTS}

The authors thank Dr. Martin Lukac (Chair of the COST Action FP1305 BioLink: Linking belowground biodiversity and ecosystem function in European forests) and Dr. Mauro Gamboni (coordinator of the working group 3 of the COST Action Biolink: Belowground biodiversity in plantations and tree crops) for their encouragement and support.

\section{SUPPLEMENTARY MATERIAL}

The Supplementary Material for this article can be found online at: https://www.frontiersin.org/articles/10.3389/fmicb. 2018.01006/full\#supplementary-material

Ancona, V., Barra Caracciolo, A., Grenni, P., Di Lenola, M., Campanale, C., Calabrese, A., et al. (2017). Plant-assisted bioremediation of a historically PCB and heavy metal-contaminated area in Southern Italy. N. Biotechnol. 38, 65-73. doi: 10.1016/j.nbt.2016.09.006

Anderson, I. C., and Cairney, J. W. G. (2004). Diversity and ecology of soil fungal communities: increased understanding through the application of molecular techniques. Environ. Microbiol. 6, 769-779. doi: 10.1111/j.1462-2920.2004.00675.x

Anderson, T.-H., and Domsch, K. H. (1989). Ratios of microbial biomass carbon to total organic carbon in arable soils. Soil Biol. Biochem. 21, 471-479. doi: 10.1016/0038-0717(89)90117-X

Aranda, S., Montes-Borrego, M., Jiménez-Díaz, R. M., and Landa, B. B. (2011). Microbial communities associated with the root system of wild olives (Olea europaea L. subsp. europaea var. sylvestris) are good reservoirs of bacteria with antagonistic potential against Verticillium dahliae. Plant Soil 343, 329-345. doi: 10.1007/s11104-011-0721-2

Araújo, W. L., Marcon, J., Maccheroni, W., Van Elsas, J. D., Van Vuurde, J. W. L., and Azevedo, J. L. (2002). Diversity of endophytic bacterial populations and their interaction with Xylella fastidiosa in citrus plants. Appl. Environ. Microbiol. 68, 4906-4914. doi: 10.1128/AEM.68.10.49064914.2002

Asiegbu, F. O., Adomas, A., and Stenlid, J. (2005). Conifer root and butt rot caused by Heterobasidion annosum (Fr.) Bref. s.l. Mol. Plant Pathol. 6, 395-409. doi: 10.1111/j.1364-3703.2005.00295.x

Aßhauer, K. P., Wemheuer, B., Daniel, R., and Meinicke, P. (2015). Tax4Fun: predicting functional profiles from metagenomic $16 \mathrm{~S}$ rRNA data. Bioinformatics 31, 2882-2884. doi: 10.1093/bioinformatics/btv287

Augspurger, C. K., and Wilkinson, H. T. (2007). Host specificity of pathogenic Pythium species: implications for tree species diversity. Biotropica 39, 702-708. doi: 10.1111/j.1744-7429.2007.00326.x

Azarbad, H., Niklinska, M., Laskowski, R., van Straalen, N. M., van Gestel, C. A. M., Zhou, J., et al. (2015). Microbial community composition and functions are resilient to metal pollution along two forest soil gradients. FEMS Microbiol. Ecol. 91, 1-11. doi: 10.1093/femsec/fiu003 
Bagwell, C. E., Dantzler, M., Bergholz, P. W., and Lovell, C. R. (2001). Hostspecific ecotype diversity of rhizoplane diazotrophs of the perennial glasswort Salicornia virginica and selected salt marsh grasses. Aquat. Microb. Ecol. 23, 293-300. doi: 10.3354/ame023293

Bais, H. P., Weir, T. L., Perry, L. G., Gilroy, S., and Vivanco, J. M. (2006). The role of root exudates in rhizosphere interations with plants and other organisms. Annu. Rev. Plant Biol. 57, 233-266. doi: 10.1146/annurev.arplant.57.032905.105159

Bakker, P. A. H. M., Berendsen, R. L., Doornbos, R. F., Wintermans, P. C. A., and Pieterse, C. M. J. (2013). The rhizosphere revisited: root microbiomics. Front. Plant Sci. 4:165. doi: 10.3389/fpls.2013.00165

Baldrian, P., Kolairík, M., Štursová, M., Kopecký, J., Valášková, V., Větrovský, T., et al. (2012). Active and total microbial communities in forest soil are largely different and highly stratified during decomposition. ISME J. 6, 248-258. doi: 10.1038/ismej.2011.95

Barberán, A., Bates, S. T., Casamayor, E. O., and Fierer, N. (2012). Using network analysis to explore co-occurrence patterns in soil microbial communities. ISME J. 6, 343-351. doi: 10.1038/ismej.2011.119

Barra Caracciolo, A., Bottoni, P., and Grenni, P. (2010). Fluorescence in situ hybridization in soil and water ecosystems: a useful method for studying the effect of xenobiotics on bacterial community structure. Toxicol. Environ. Chem. 92, 567-579. doi: 10.1080/02772241003620244

Barra Caracciolo, A., Bustamante, M. A., Nogues, I., Di Lenola, M., Luprano, M. L., and Grenni, P. (2015). Changes in microbial community structure and functioning of a semiarid soil due to the use of anaerobic digestate derived composts and rosemary plants. Geoderma 245-246, 89-97. doi: 10.1016/j.geoderma.2015.01.021

Barra Caracciolo, A., Grenni, P., Cupo, C., and Rossetti, S. (2005). In situ analysis of native microbial communities in complex samples with high particulate loads. FEMS Microbiol. Lett. 253, 55-58. doi: 10.1016/j.femsle.2005. 09.018

Bastian, M., Heymann, S., and Jacomy, M. (2009). "Gephi: an open source software for exploring and manipulating networks," in International AAAI Conference on Weblogs and Social Media (San Jose, CA).

Bastida, F., Kandeler, E., Moreno, J. L., Ros, M., García, C., and Hernández, T. (2008). Application of fresh and composted organic wastes modifies structure, size and activity of soil microbial community under semiarid climate. Appl. Soil Ecol. 40, 318-329. doi: 10.1016/j.apsoil.2008.05.007

Baum, C., Eckhardt, K. U., Hahn, J., Weih, M., Dimitriou, I., and Leinweber, P. (2013). Impact of poplar on soil organic matter quality and microbial communities in arable soils. Plant Soil Environ. 59, 95-100. doi: 10.17221/548/2012-PSE

Baum, C., Hrynkiewicz, K., Leinweber, P., and Meißner, R. (2006). Heavy-metal mobilization and uptake by mycorrhizal and nonmycorrhizal willows (Salix $\mathrm{x}$ dasyclados). J. Plant Nutr. Soil Sci. 169, 516-522. doi: 10.1002/jpln.200521925

Baumgartner, K., Coetzee, M. P. A., and Hoffmeister, D. (2011). Secrets of the subterranean pathosystem of Armillaria. Mol. Plant Pathol. 12, 515-534. doi: 10.1111/j.1364-3703.2010.00693.x

Beckers, B., De Beeck, M. O., Weyens, N., Boerjan, W., and Vangronsveld, J. (2017). Structural variability and niche differentiation in the rhizosphere and endosphere bacterial microbiome of field-grown poplar trees. Microbiome 5:25. doi: 10.1186/s40168-017-0241-2

Behie, S. W., Zelisko, P. M., and Bidochka, M. J. (2012). Endophytic insectparasitic fungi translocate nitrogen directly from insects to plants. Science 336, 1576-1577. doi: 10.1126/science.1222289

Berg, G., Grube, M., Schloter, M., and Smalla, K. (2014). The plant microbiome and its importance for plant and human health. Front. Microbiol. 5:491. doi: 10.3389/fmicb.2014.00491

Berg, G., Köberl, M., Rybakova, D., Müller, H., Grosch, R., and Smalla, K. (2017). Plant microbial diversity is suggested as the key to future biocontrol and health trends. FEMS Microbiol. Ecol. 93:fix050. doi: 10.1093/femsec/fix050

Berlanger, I., and Powelson, M. L. (2000). Verticillium wilt. Plant Heal. Instr. doi: 10.1094/PHI-I-2000-0801-01

Berruti, A., Lumini, E., Balestrini, R., and Bianciotto, V. (2015). Arbuscular mycorrhizal fungi as natural biofertilizers: let's benefit from past successes. Front. Microbiol. 6:1559. doi: 10.3389/fmicb.2015.01559

Bevivino, A., and Dalmastri, C. (2017). "Impact of agricultural land management on soil bacterial community: a case study in the Mediterranean area," in Soil
Biological Communities and Ecosystem Resilience, Sustainability in Plant and Crop Protection Series, eds M. Lukac, P. Grenni, and M. Gamboni (Switzerland: Springer International Publishing AG), 77-95.

Bevivino, A., Paganin, P., Bacci, G., Florio, A., Pellicer, M. S., Papaleo, M. C., et al. (2014). Soil bacterial community response to differences in agricultural management along with seasonal changes in a Mediterranean region. PLoS ONE 9: e105515. doi: 10.1371/journal.pone.0105515

Bhore, S., Christina, A., and Christapher, V. (2013). Endophytic bacteria as a source of novel antibiotics: an overview. Pharmacogn. Rev. 7:11. doi: 10.4103/0973-7847.112833

Blagodatskaya, E., and Kuzyakov, Y. (2013). Active microorganisms in soil: critical review of estimation criteria and approaches. Soil Biol. Biochem. 67, 192-211. doi: 10.1016/j.soilbio.2013.08.024

Bonilla, N., Vida, C., Martínez-Alonso, M., Landa, B. B., Gaju, N., Cazorla, F. M., et al. (2015). Organic amendments to avocado crops induce suppressiveness and influence the composition and activity of soil microbial communities. Appl. Environ. Microbiol. 81, 3405-3418. doi: 10.1128/AEM.03787-14

Borkowska, B. (2002). Growth and photosynthetic activity of micropropagated strawberry plants inoculated with endomycorrhizal fungi (AMF) and growing under drought stress. Acta Physiol. Plant. 24, 365-370. doi: 10.1007/s11738-002-0031-7

Borriss, R. (2015). "Bacillus, a plant-beneficial bacterium," in Principles of PlantMicrobe Interactions: Microbes for Sustainable Agriculture, ed B. Lugtenberg (Switzerland: Springer International Publishing), 379-391.

Brader, G., Compant, S., Vescio, K., Mitter, B., Trognitz, F., Ma, L. J., et al. (2017). Ecology and genomic insights into plant-pathogenic and plant-nonpathogenic endophytes. Annu. Rev. Phytopathol. 55, 61-83. doi: 10.1146/annurev-phyto-080516-035641

Branton, D., Deamer, D. W., Marziali, A., Bayley, H., Benner, S. A., Butler, T., et al. (2008). The potential and challenges of nanopore sequencing. Nat. Biotechnol. 26, 1146-1153. doi: 10.1038/nbt.1495

Buée, M., Reich, M., Murat, C., Morin, E., Nilsson, R. H., Uroz, S., et al. (2009). 454 Pyrosequencing analyses of forest soils reveal an unexpectedly high fungal diversity. New Phytol. 184, 449-456. doi: 10.1111/j.1469-8137.2009.03003.x

Bulgarelli, D., Schlaeppi, K., Spaepen, S., van Themaat, E. V. L., and Schulze-Lefert, P. (2013). Structure and functions of the bacterial microbiota of plants. Annu. Rev. Plant Biol. 64, 807-838. doi: 10.1146/annurev-arplant-050312-120106

Burke, D. J. (2015). Effects of annual and interannual environmental variability on soil fungi associated with an old-growth, temperate hardwood forest. FEMS Microbiol. Ecol. 91:fiv053. doi: 10.1093/femsec/fiv053

Cai, F., Chen, W., Wei, Z., Pang, G., Li, R., Ran, W., et al. (2015). Colonization of Trichoderma harzianum strain SQR-T037 on tomato roots and its relationship to plant growth, nutrient availability and soil microflora. Plant Soil 388, 337-350. doi: 10.1007/s11104-014-2326-Z

Caliz, J., Montes-Borrego, M., Triadó-Margarit, X., Metsis, M., Landa, B. B., and Casamayor, E. O. (2015). Influence of edaphic, climatic, and agronomic factors on the composition and abundance of nitrifying microorganisms in the rhizosphere of commercial olive crops. PLOS ONE 10:e0125787. doi: 10.1371/journal.pone.0125787

Campos-Herrera, R., Ali, J. G., Díaz, B. M., and Duncan, L. W. (2013). Analyzing spatial patterns linked to the ecology of herbivores and their natural enemies in the soil. Frontiers Plant Sci. 4:378. doi: 10.3389/fpls.2013.00378

Campos-Herrera, R., El-Borai, F. E., and Duncan, L. (2015). "It takes a village: entomopathogenic nematode community structure and conservation biological control in Florida (US) orchards," in Nematode Pathogenesis of Insects and Other Pests - Ecology and Applied Technologies for Sustainable Plant and Crop Protection, Sustainability in Plant and Crop Protection Series, ed R. Campos-Herrera (Switzerland: Springer International Publishing), 327-349.

Campos-Herrera, R., El-Borai, F. E., Ebert, T. E., Schumann, A., and Duncan, L. W. (2014). Management to control citrus greening alters the soil food web and severity of a pest-disease complex. Biol. Control 76, 41-51. doi: 10.1016/j.biocontrol.2014.04.012

Carrero-Carrón, I., Trapero-Casas, J. L., Olivares-García, C., Monte, E., Hermosa, R., and Jiménez-Díaz, R. M. (2016). Trichoderma asperellum is effective for biocontrol of Verticillium wilt in olive caused by the defoliating pathotype of Verticillium dahliae. Crop Prot. 88, 45-52. doi: 10.1016/j.cropro.2016. 05.009 
Carvalhais, L. C., Dennis, P. G., Tyson, G. W., and Schenk, P. M. (2012). Application of metatranscriptomics to soil environments. J. Microbiol. Methods 91, 246-251. doi: 10.1016/j.mimet.2012.08.011

Castillo, J., Lawrence, K., Kloepper, J., and van Santen, E. (2010). Evaluation of Drechslerra dactyloides, Drechslerella brochopaga, and Paecilomyces lilacinus for biocontrol of Rotylenchulus reniformis. Nematropica 40, 71-86. Available online at: http://journals.fcla.edu/nematropica/article/view/64499

Cavé, L., Brothier, E., Abrouk, D., Bouda, P. S., Hien, E., and Nazaret, S. (2016). Efficiency and sensitivity of the digital droplet PCR for the quantification of antibiotic resistance genes in soils and organic residues. Appl. Microbiol. Biotechnol. 100, 10597-10608. doi: 10.1007/s00253-016-7950-5

Cazorla, F. M., and Mercado-Blanco, J. (2016). Biological control of tree and woody plant diseases: an impossible task? BioControl 61, 233-242. doi: 10.1007/s10526-016-9737-0

Cazorla, F. M., Duckett, S. B., Bergström, E. T., Noreen, S., Odijk, R., Lugtenberg, B. J. J., et al. (2006). Biocontrol of avocado dematophora root rot by antagonistic Pseudomonas fluorescens PCL1606 correlates with the production of 2-hexyl 5-propyl resorcinol. Mol. Plant. Microbe Interact. 19, 418-428. doi: 10.1094/MPMI-19-0418

Cazorla, F. M., Romero, D., Pérez-García, A., Lugtenberg, B. J. J., Vicente, A., and Bloemberg, G. (2007). Isolation and characterization of antagonistic Bacillus subtilis strains from the avocado rhizoplane displaying biocontrol activity. J. Appl. Microbiol. 103, 1950-1959. doi: 10.1111/j.1365-2672.2007.03433.x

Ciancio, A. (1995). Density-dependent parasitism of Xiphinema-diversicaudatum by Pasteuria-penetrans in a naturally infested field. Phytopathology 85, 144-149. doi: 10.1094/Phyto-85-144

Ciancio, A., Colagiero, M., Ferrara, M., Nigro, F., Pentimone, I., and Rosso, L. (2013). "Transcriptome changes in tomato roots during colonization by the endophytic fungus Pochonia," in 5th Congress of European Microbiologists (FEMS) (Leipzig).

Ciancio, A., Roccuzzo, G., and Longaron, C. O. (2016). Regulation of the citrus nematode Tylenchulus semipenetrans by a Pasteuria sp. endoparasite in a naturally infested soil. BioControl 61, 337-347. doi: 10.1007/s10526-0159704-1

Colagiero, M., Pentimone, I., Rosso, L., and Ciancio, A. (2017). “A metagenomic study on the effect of aboveground plant cover on soil bacterial diversity," in Soil Biological Communities and Ecosystem Resilience, Sustainability in Plant and Crop Protection Series, eds M. Lukac, P. Grenni, and M. Gamboni (Switzerland: Springer International Publishing AG), 97-106.

Conn, C., and Dighton, J. (2000). Litter quality influences on decomposition, ectomycorrhizal community structure and mycorrhizal root surface acid phosphatase activity. Soil Biol. Biochem. 32, 489-496. doi: 10.1016/S0038-0717(99)00178-9

Damon, C., Lehembre, F., Oger-Desfeux, C., Luis, P., Ranger, J., FraissinetTachet, L., et al. (2012). Metatranscriptomics reveals the diversity of genes expressed by eukaryotes in forest soils. PLOS ONE 7:e28967. doi: 10.1371/journal.pone.0028967

D'Arcy, C. J. (2000). Dutch elm disease. Plant Heal. Instr. 2-4. doi: 10.1094/PHI-I-2000-0721-02. Available online at: https://www.apsnet.org/ edcenter/intropp/lessons/fungi/ascomycetes/Pages/DutchElm.aspx

Dawson, J. O. (2008). "Ecology of ctinorhizal plants," in Nitrogen-Fixing Actinorhizal Symbioses. Nitrogen Fixation: Origins, Applications, and Research Progress, eds K. Pawlowski and W. Newton (Springer), 199-234.

Debode, J., De Tender, C., Soltaninejad, S., Van Malderghem, C., Haegeman, A., Van der Linden, I., et al. (2016). Chitin mixed in potting soil alters lettuce growth, the survival of zoonotic bacteria on the leaves and associated rhizosphere microbiology. Front. Microbiol. 7:565. doi: $10.3389 /$ fmicb. 2016.00565

Deketelaere, S., Tyvaert, L., França, S. C., and Hofte, M. (2017). Desirable traits of a good biocontrol agent against Verticillium wilt. Front. Microbiol. 8:1186. doi: 10.3389/fmicb.2017.01186

del Mar Alguacil, M., Torrecillas, E., Lozano, Z., and Roldán, A. (2011). Evidence of differences between the communities of arbuscular mycorrhizal fungi colonizing galls and roots of Prunus persica infected by the root-knot nematode Meloidogyne incognita. Appl. Environ. Microbiol. 77, 8656-8661. doi: 10.1128/AEM.05577-11

Di Lenola, M., Grenni, P., Proença, D., Morais, P., and Barra Caracciolo, A. (2017). "Comparison of two molecular methods to assess soil microbial diversity," in Soil Biological Communities and Ecosystem Resilience, Sustainability in Plant and Crop Protection Series, eds M. Lukac, P. Grenni, and M. Gamboni (Switzerland: Springer International Publishing AG), 25-42.

Diánez Martínez, F., Santos, M., Carretero, F., and Marín, F. (2016). Trichoderma saturnisporum, a new biological control agent. J. Sci. Food Agric. 96, 1934-1944. doi: $10.1002 /$ jsfa.7301

Diem, H., and Dommergues, Y. (1990). "Current and potential uses and management of Casuarinaceae in the tropics and subtropics," in The Biology of Frankia and Actinorhizal Plants, eds C. Schwintzer and J. Tjepkema (San Diego, CA: Academic Press), 317-342.

Djonović, S., Pozo, M. J., and Kenerley, C. M. (2006). Tvbgn3, a $\beta$-1,6-glucanase from the biocontrol fungus Trichoderma virens, is involved in mycoparasitism and control of Pythium ultimum. Appl. Environ. Microbiol. 72, 7661-7670. doi: 10.1128/AEM.01607-06

Doornbos, R. F., van Loon, L. C., and Bakker, P. A. H. M. (2012). Impact of root exudates and plant defense signaling on bacterial communities in the rhizosphere. A review. Agron. Sustain. Dev. 32, 227-243. doi: 10.1007/s13593-011-0028-y

Doty, S. L., Oakley, B., Xin, G., Kang, J. W., Singleton, G., Khan, Z., et al. (2009). Diazotrophic endophytes of native black cottonwood and willow. Symbiosis 47, 23-33. doi: 10.1007/BF03179967

Dumas, M. T., and Boyonoski, N. W. (1992). Scanning electron microscopy of mycoparasitism of Armillaria rhizomorphs by species of Trichoderma. Eur. J. For. Pathol. 22, 379-383. doi: 10.1111/j.1439-0329.1992.tb00310.x

Erwin, D. C., Bartnicki-García, S., Tsao, P. H., and Society, A. P. (1983). Phytophthora: its Biology, Taxonomy, Ecology, and Pathology. American Phytopathological Society. Available online at: https://books.google.it/books? id=34MMAQAAMAAJ

Fakruddin, M. D., and Mannan, K. S. B. (2013). Methods for analyzing diversity of microbial communities in natural environments. Ceylon J. Sci. 42, 19-33. doi: $10.4038 /$ cjsbs.v42i1.5896

Farkas, K., Hassard, F., McDonald, J. E., Malham, S. K., and Jones, D. L. (2017). Evaluation of molecular methods for the detection and quantification of pathogen-derived nucleic acids in sediment. Front. Microbiol. 8:53. doi: $10.3389 /$ fmicb. 2017.00053

Felsmann, K., Baudis, M., Gimbel, K., Kayler, Z. E., Ellerbrock, R., Bruehlheide, H., et al. (2015). Soil bacterial community structure responses to precipitation reduction and forest management in forest ecosystems across Germany. PLoS ONE 10:e0122539. doi: 10.1371/journal.pone.0122539

Fierer, N. (2017). Embracing the unknown: disentangling the complexities of the soil microbiome. Nat. Rev. Microbiol. 15, 579. doi: 10.1038/nrmicro.2017.87

Fierer, N., Leff, J. W., Adams, B. J., Nielsen, U. N., Bates, S. T., Lauber, C. L., et al. (2012). Cross-biome metagenomic analyses of soil microbial communities and their functional attributes. Proc. Natl. Acad. Sci. U.S.A. 109, 21390-21395. doi: 10.1073/pnas.1215210110

Fox, R. T. V. (2003). Managing Armillaria root rot. J. Food Agric. Environ. 1, 95-100.

Francisco, R., Stone, D., Creamer, R. E., Sousa, J. P., and Morais, P. V. (2016). European scale analysis of phospholipid fatty acid composition of soils to establish operating ranges. Appl. Soil Ecol. 97, 49-60. doi: 10.1016/j.apsoil.2015.09.001

Franken, E., Krieger, L., and Schnetter, W. (1996). Bacillus popilliae: a difficult pathogen . Integrated control of soil pests. IOBC/WPRS Bulletin 19, 40-45.

Gamalero, E., Cesaro, P., Cicatelli, A., Todeschini, V., Musso, C., Castiglione, S., et al. (2012). Poplar clones of different sizes, grown on a heavy metal polluted site, are associated with microbial populations of varying composition. Sci. Total Environ. 425, 262-270. doi: 10.1016/j.scitotenv.2012.03.012

Garland, J. L., and Mills, A. L. (1991). Classification and characterization of heterotrophic microbial communities on the basis of patterns of communitylevel sole-carbon-source utilization. Appl. Environ. Microbiol. 57, 2351-2359.

Gehring, C. A., Mueller, R. C., Haskins, K. E., Rubow, T. K., and Whitham, T. G. (2014). Convergence in mycorrhizal fungal communities due to drought, plant competition, parasitism, and susceptibility to herbivory: consequences for fungi and host plants. Front. Microbiol. 5:306. doi: 10.3389/fmicb.2014.00306

Giuma, A. Y., and Cooke, R. C. (1971). Nematotoxin production by Nematoctonus haptocladus and N. concurrens. Trans. Br. Mycol. Soc. 56, 89-94.

Gómez-Lama Cabanás, C., Legarda, G., Ruano-Rosa, D., Pizarro-Tobías, P., Valverde-Corredor, A., Niqui, J. L., et al. (2018). Indigenous Pseudomonas spp. 
strains from the olive (Olea europaea L.) rhizosphere as effective biocontrol agents against Verticillium dahliae: From the host roots to the bacterial genomes. Front. Microbiol. 9:277. doi: 10.3389/fmicb.2018.00277

Gómez-Lama Cabanás, C., Sesmero, R., Valverde-Corredor, A., LópezEscudero, F. J., and Mercado-Blanco, J. (2017). A split-root system to assess biocontrol effectiveness and defense-related genetic responses in above-ground tissues during the tripartite interaction Verticillium dahliaeolive-Pseudomonas fluorescens PICF7 in roots. Plant Soil 417, 433-452. doi: 10.1007/s11104-017-3269-y

Gopal, M., Gupta, A., and Thomas, G. V. (2013). Bespoke microbiome therapy to manage plant diseases. Front. Microbiol. 4:355. doi: 10.3389/fmicb.2013. 00355

Gottel, N. R., Castro, H. F., Kerley, M., Yang, Z., Pelletier, D. A., Podar, M., et al. (2011). Distinct microbial communities within the endosphere and rhizosphere of Populus deltoides roots across contrasting soil types. Appl. Environ. Microbiol. 77, 5934-5944. doi: 10.1128/AEM.05255-11

Gravel, V., Antoun, H., and Tweddell, R. J. (2007). Growth stimulation and fruit yield improvement of greenhouse tomato plants by inoculation with Pseudomonas putida or Trichoderma atroviride: possible role of indole acetic acid (IAA). Soil Biol. Biochem. 39, 1968-1977. doi: 10.1016/j.soilbio.2007. 02.015

Grayston, S. J., Wang, S., Campbell, C. D., and Edwards, A. C. (1998). Selective influence of plant species on microbial diversity in the rhizosphere. Soil Biol. Biochem. 30, 369-378. doi: 10.1016/S0038-0717(97)00124-7

Haegeman, A., Vanholme, B., Jacob, J., Vandekerckhove, T. T. M., Claeys, M., Borgonie, G., et al. (2009). An endosymbiotic bacterium in a plant-parasitic nematode: member of a new Wolbachia supergroup. Int. J. Parasitol. 39, 1045-1054. doi: 10.1016/j.ijpara.2009.01.006

Handelsman, J., Rondon, M. R., Brady, S. F., Clardy, J., and Goodman, R. M. (1998). Molecular biological access to the chemistry of unknown soil microbes: a new frontier for natural products. Chem. Biol. 5, R245-R249. doi: 10.1016/S1074-5521(98)90108-9

Hardoim, P. R., van Overbeek, L. S., Berg, G., Pirttilä, A. M., Compant, S., Campisano, A., et al. (2015). The hidden world within plants: ecological and evolutionary considerations for defining functioning of microbial endophytes. Microbiol. Mol. Biol. Rev. 79, 293-320. doi: 10.1128/MMBR. 00050-14

Hartmann, M., Howes, C. G., Vaninsberghe, D., Yu, H., Bachar, D., Christen, R., et al. (2012). Significant and persistent impact of timber harvesting on soil microbial communities in Northern coniferous forests. ISME J. 6, 2199-2218. doi: 10.1038 /ismej.2012.84

Hartmann, M., Niklaus, P. A., Zimmermann, S., Schmutz, S., Kremer, J., Abarenkov, K., et al. (2014). Resistance and resilience of the forest soil microbiome to logging-associated compaction. ISME J. 8, 226-244. doi: 10.1038/ismej.2013.141

Hashem, A., Abd-Allah, E. F., Alqarawi, A. A., Al-Huqail, A. A., Wirth, S., and Egamberdieva, D. (2016). The interaction between arbuscular mycorrhizal fungi and endophytic bacteria enhances plant growth of Acacia gerrardii under salt stress. Front. Microbiol. 7:1089. doi: 10.3389/fmicb.2016.01089

Hassan, S. E. D., Bell, T. H., Stefani, F. O. P., Denis, D., Hijri, M., and St-Arnaud, M. (2014). Contrasting the community structure of arbuscular mycorrhizal fungi from hydrocarbon-contaminated and uncontaminated soils following willow (Salix spp. L.) planting. PLoS ONE 9:e102838. doi: 10.1371/journal.pone.0102838

Hatvani, L., Kocsubé, S., Manczinger, L., Antal, Z., and Szekeres, A. (2008). “The green mould disease global threat to the cultivation of oyster mushroom (Pleurotus ostreatus): a review," in Science and Cultivation of Edible and Medicinal Fungi: Mushroom Science XVII, Proceedings of the 17th Congress of the International Society for Mushroom Science ed M. Gruening (Cape Town), $17,485-495$

Hatvani, L., Manczinger, L., Vágvölgyi, C., and Kredrics, L. (2013). “Trichoderma as a human pathogen," in Trichoderma: Biology and Applications eds P. K. Mukherjee, B. A. Horwitz, U. S Singh, M. Mukherjee, and M. Schmoll (Wallingford: CABI Publishing International), 292-313.

Hesse, C. N., Mueller, R. C., Vuyisich, M., Gallegos-Graves, L. V., Gleasner, C. D., Zak, D. R., et al. (2015). Forest floor community metatranscriptomes identify fungal and bacterial responses to $\mathrm{N}$ deposition in two maple forests. Front. Microbiol. 6:337. doi: 10.3389/fmicb.2015.00337
Hiemstra, J., and Harris, D. (1998). A compendium of Verticillium wilts in tree species. Wageningen: Ponsen \& Looijen Available online at: http://edepot.wur. $\mathrm{nl} / 211512$

Hietala, A. M., and Sen, R. (1996). "Rhizoctonia associated with forest trees," in Rhizoctonia Species: Taxonomy, Molecular Biology, Ecology, Pathology and Disease Control, eds B. Sneh, S. Jabaji-Hare, S. Neate, and G. Dijst (Dordrecht: Springer), 351-358. doi: 10.1007/978-94-017-2901-7_32

Hill, G. T., Mitkowski, N. A., Aldrich-Wolfe, L., Emele, L. R., Jurkonie, D. D., Ficke, A., et al. (2000). Methods for assessing the composition and diversity of soil microbial communities. Appl. Soil Ecol. 15, 25-36. doi: 10.1016/S0929-1393(00)00069-X

Hinojosa, M. B., Parra, A., Laudicina, V. A., and Moreno, J. M. (2016). Postfire soil functionality and microbial community structure in a Mediterranean shrubland subjected to experimental drought. Sci. Total Environ. 573, 1178-1189. doi: 10.1016/j.scitotenv.2016.03.117

Hinsinger, P., Bengough, A. G., Vetterlein, D., and Young, I. M. (2009). Rhizosphere: biophysics, biogeochemistry and ecological relevance. Plant Soil 321, 117-152. doi: 10.1007/s11104-008-9885-9

Hrynkiewicz, K., and Baum, C. (2012). "The potential of rhizosphere microorganisms to promote the plant growth in disturbed soils," in Environmental Protection Strategies for Sustainable Development, Strategies for Sustainability Series, eds A. Malik and E. Grohmann (Dordrecht: Springer), 35-64.

Hrynkiewicz, K., Baum, C., Leinweber, P., Weih, M., and Dimitriou, I. (2010). The significance of rotation periods for mycorrhiza formation in short rotation coppice. For. Ecol. Manage. 260, 1943-1949. doi: 10.1016/j.foreco.2010.08.020

Hrynkiewicz, K., Baum, C., Niedojadło, J., and Dahm, H. (2009). Promotion of mycorrhiza formation and growth of willows by the bacterial strain Sphingomonas sp. 23L on fly ash. Biol. Fertil. Soils 45, 385-394. doi: 10.1007/s00374-008-0346-7

Hrynkiewicz, K., Dabrowska, G., Baum, C., Niedojadlo, K., and Leinweber, P. (2012). Interactive and single effects of ectomycorrhiza formation and Bacillus cereus on metallothionein MT1 expression and phytoextraction of Cd and Zn by willows. Water. Air. Soil Pollut. 223, 957-968. doi: 10.1007/s11270-011-0915-5

Hrynkiewicz, K., Szymańska, S., Piernik, A., and Thiem, D. (2015). Ectomycorrhizal community structure of Salix and Betula spp. at a saline site in central Poland in relation to the seasons and soil parameters. Water. Air. Soil Pollut. 226:99. doi: 10.1007/s11270-015-2308-7

Hwang, E. E., Wang, M. B., Bravo, J. E., and Banta, L. M. (2015). Unmasking host and microbial strategies in the Agrobacterium-plant defense tango. Front. Plant Sci. 6:200. doi: 10.3389/fpls.2015.00200

Imperiali, N., Chiriboga, X., Schlaeppi, K., Fesselet, M., Villacrés, D., Jaffuel, G., et al. (2017). Combined field inoculations of pseudomonas bacteria, arbuscular mycorrhizal fungi, and entomopathogenic nematodes and their effects on wheat performance. Front. Plant Sci. 8:1809. doi: 10.3389/fpls.2017.01809

Inderbitzin, P., Bostock, R. M., Davis, R. M., Usami, T., Platt, H. W., and Subbarao, K. V. (2011). Phylogenetics and taxonomy of the fungal vascular wilt pathogen Verticillium, with the descriptions of five new species. PLoS ONE 6:e28341. doi: 10.1371/journal.pone.0028341

Ingham, E. R. (1999). "The soil food web," in The Soil Biology Primer - Chapter 1, eds A. J. Tugel, A. M. Lewandowski, and D. Happe-vonArb (Ames, IA: USDA, Natural Resources Conservation Service, Soil Quality Institute), 48.

Islam, F., and Ohga, S. (2013). Effects of media formulation on the growth and morphology of ectomycorrhizae and their association with host plant. ISRN Agron. 2013, 1-12. doi: 10.1155/2013/317903

Jackson, T., and Zimmermann, G. (1996). Is there a role for Serratia spp. in the biocontrol of Melolontha spp? IOBC/WPRS Bulletin 19, 47-54.

Jaffee, B. A. (1992). Population biology and biological control of nematodes. Can. J. Microbiol. 38, 359-364. doi: 10.1139/m92-061

Jaffee, B. A., Gaspard, J. T., and Ferris, H. (1989). Density-dependent parasitism of the soil-borne nematode Criconemella xenoplax by the nematophagous fungus Hirsutella rhossiliensis. Microb. Ecol. 17, 193-200. doi: 10.1007/BF02011853

Janssen, P. H. (2006). Identifying the dominant soil bacterial taxa in libraries of 16S rRNA and 16S rRNA genes. Appl. Environ. Microbiol. 72, 1719-1728. doi: 10.1128/AEM.72.3.1719-1728.2006

Jung, T., and Burgess, T. I. (2009). Re-evaluation of Phytophthora citricola isolates from multiple woody hosts in Europe and North America reveals a new species, 
Phytophthora plurivora sp. nov. Persoonia. Mol. Phylogeny Evol. Fungi 22, 95-110. doi: 10.3767/003158509X442612

Kandel, S. L., Herschberger, N., Kim, S. H., and Doty, S. L. (2015). Diazotrophic endophytes of poplar and willow for growth promotion of rice plants in nitrogen-limited conditions. Crop Sci. 55, 1765-1772. doi: 10.2135/cropsci2014.08.0570

Kang, J. W., Khan, Z., and Doty, S. L. (2012). Biodegradation of trichloroethylene by an endophyte of hybrid poplar. Appl. Environ. Microbiol. 78, 3504-3507. doi: 10.1128/AEM.06852-11

Kapulnik, Y., Tsror, L., Zipori, I., Hazanovsky, M., Wininger, S., and Dag, A. (2010). Effect of AMF application on growth, productivity and susceptibility to Verticillium wilt of olives grown under desert conditions. Symbiosis 52, 103-111. doi: 10.1007/s13199-010-0085-Z

Kati, H., Sezen, K., and Demirbag, Z. (2007). Characterization of a highly pathogenic Bacillus thuringiensis strain isolated from common cockchafer, Melolontha melolontha. Folia Microbiol. 52, 146-152. doi: 10.1007/BF02932153

Kerr, A. (2016). Biological control of crown gall. Australas. Plant Pathol. 45, 15-18. doi: $10.1007 /$ s13313-015-0389-9

Khabou, W., Hajji, B., Zouari, M., Rigane, H., and Abdallah, F. B. (2014). Arbuscular mycorrhizal fungi improve growth and mineral uptake of olive tree under gypsum substrate. Ecol. Eng. 73, 290-296. doi: 10.1016/j.ecoleng.2014.09.054

Kim, T. G., Jeong, S. Y., and Cho, K. S. (2014). Comparison of droplet digital PCR and quantitative real-time PCR for examining population dynamics of bacteria in soil. Appl. Microbiol. Biotechnol. 98, 6105-6113. doi: 10.1007/s00253-014-5794-4

Kluepfel, D. A., Nyczepir, A. P., Lawrence, J. E., Wechter, W. P., and Leverentz, B. (2002). Biological control of the phytoparasitic nematode Mesocriconema xenoplax on peach trees. J. Nematol. 34, 120-123. Available online at: http:// journals.fcla.edu/jon/article/view/67308

Knief, C. (2014). Analysis of plant microbe interactions in the era of next generation sequencing technologies. Front. Plant Sci. 5:216. doi: $10.3389 /$ fpls.2014.00216

Knoth, J. L., Kim, S.-H., Ettl, G. J., and Doty, S. L. (2014). Biological nitrogen fixation and biomass accumulation withinpoplar clones as a result of inoculations with diazotrophicendophyte consortia. New Phytol. 201, 599-609. doi: $10.1111 /$ nph. 12536

Konopka, A., Oliver, L., and Turco, R. F. J. (1998). The use of carbon substrate utilization patterns in environmental and ecological microbiology. Microb. Ecol. 35, 103-115. doi: 10.1007/s002489900065

Kowalski, K. P., Bacon, C., Bickford, W., Braun, H., Clay, K., Leduc-Lapierre, M., et al. (2015). Advancing the science of microbial symbiosis to support invasive species management: a case study on Phragmites in the Great Lakes. Front. Microbiol. 6:95. doi: 10.3389/fmicb.2015.00095

Kredics, L., García Jimenez, L., Naeimi, S., Czifra, D., Urbán, P., Manczinger, L., et al. (2010). "A challenge to mushroom growers: the green mould disease of cultivated champignons" in Current Research, Technology and Education Topics in Applied Microbiology and Microbial Biotechnology, ed A. Mendez-Vilas (Microbiology book series-number 2, Formatex Research Center), 295-305. Available online at: http://www.formatex.org/microbiology2/

Kuklinsky-Sobral, J., Araújo, W. L., Mendes, R., Pizzirani-Kleiner, A. A., and Azevedo, J. L. (2005). Isolation and characterization of endophytic bacteria from soybean (Glycine max) grown in soil treated with glyphosate herbicide. Plant Soil 273, 91-99. doi: 10.1007/s11104-004-6894-1

Kutter, S., Hartmann, A., and Schmid, M. (2006). Colonization of barley (Hordeum vulgare) with Salmonella enterica and Listeria spp. FEMS Microbiol. Ecol. 56, 262-271. doi: 10.1111/j.1574-6941.2005.00053.x

Lakshmanan, V., Selvaraj, G., and Bais, H. P. (2014). Functional soil microbiome: belowground solutions to an aboveground problem. Plant Physiol. 166, 689-700. doi: 10.1104/pp.114.245811

Langille, M., Zaneveld, J., Caporaso, J. G., McDonald, D., Knights, D., Reyes, J., et al. (2013). Predictive functional profiling of microbial communities using 16S rRNA marker gene sequences. Nat. Biotechnol. 31, 814-821. doi: $10.1038 /$ nbt.2676

Larriba, E., Jaime, M. D. L. A., Carbonell-Caballero, J., Conesa, A., Dopazo, J., Nislow, C., et al. (2014). Sequencing and functional analysis of the genome of a nematode egg-parasitic fungus, Pochonia chlamydosporia. Fungal Genet. Biol. 65, 69-80. doi: 10.1016/j.fgb.2014.02.002
Larriba, E., Jaime, M. D. L. A., Nislow, C., Martín-Nieto, J., and Lopez-Llorca, L. V. (2015). Endophytic colonization of barley (Hordeum vulgare) roots by the nematophagous fungus Pochonia chlamydosporia reveals plant growth promotion and a general defense and stress transcriptomic response. J. Plant Res. 128, 665-678. doi: 10.1007/s10265-015-0731-x

Lederberg, J. (2006). The microbe's contribution to biology-50 years after. Int. Microbiol. 9, 155-156.

Lee, B. D., Dutta, S., Ryu, H., Yoo, S. J., Suh, D. S., and Park, K. (2015). Induction of systemic resistance in panax ginseng against Phytophthora cactorum by native Bacillus amyloliquefaciens HK34. J. Ginseng Res. 39, 213-220. doi: 10.1016/j.jgr.2014.12.002

Lehr, N., Schrey, S. D., Hampp, R., and Tarkka, M. T. (2008). Root inoculation with a forest soil streptomycete leads to locally and systemically increased resistance against phytopathogens in Norway spruce. New Phytol. 177, 965-976. doi: 10.1111/j.1469-8137.2007.02322.x

Leveau, J. H. J. (2007). "The magic and menace of metagenomics: prospects for the study of plant growth-promoting rhizobacteria," in New Perspectives and Approaches in Plant Growth-Promoting Rhizobacteria Research, eds P. A. H. M Bakker, J. M. Raaijmakers, G. Bloemberg, M. Höfte, P. Lemanceau, and B. M. Cooke (Springer), 279-300.

Lew, S., Lew, M., Mieszczynski, T., and Szarek, J. (2010). Selected fluorescent techniques for identification of the physiological state of individual water and soil bacterial cells - review. Folia Microbiol. 55, 107-118. doi: 10.1007/s12223-010-0017-6

Lewis, E. E., Hazir, S., Hodson, A., and Gulcu, B. (2015). “Trophic relationships of entomopathogenic nematodes in agricultural habitats," in Nematode Pathogenesis of Insects and Other Pests: Ecology and Applied Technologies for Sustainable Plant and Crop Protection, ed R. Campos-Herrera (Switzerland: Springer International Publishing), 139-163.

Liang, Y., Meggo, R., Hu, D., Schnoor, J. L., and Mattes, T. E. (2014). Enhanced polychlorinated biphenyl removal in a switchgrass rhizosphere by bioaugmentation with Burkholderia xenovorans LB400. Ecol. Eng. 71, 215-222. doi: 10.1016/j.ecoleng.2014.07.046

Liao, H. L., Chen, Y., Bruns, T. D., Peay, K. G., Taylor, J. W., Branco, S., et al. (2014). Metatranscriptomic analysis of ectomycorrhizal roots reveals genes associated with Piloderma-Pinus symbiosis: improved methodologies for assessing gene expression in situ. Environ. Microbiol. 16, 3730-3742. doi: $10.1111 / 1462-2920.12619$

Licht, L. A., and Isebrands, J. G. (2005). Linking phytoremediated pollutant removal to biomass economic opportunities. Biomass Bioenergy 28, 203-218. doi: 10.1016/j.biombioe.2004.08.015

Lindahl, B. D., Nilsson, R. H., Tedersoo, L., Abarenkov, K., Carlsen, T., Kjøller, R., et al. (2013). Fungal community analysis by high-throughput sequencing of amplified markers-a user's guide. New Phytol. 199, 288-299. doi: $10.1111 /$ nph.12243

Links, M. G., Dumonceaux, T. J., Hemmingsen, S. M., and Hill, J. E. (2012). The chaperonin-60 universal target is a barcode for bacteria that enables de novo assembly of metagenomic sequence data. PLOS ONE 7:e49755. doi: 10.1371/journal.pone.0049755

Lladó, S., and Baldrian, P. (2017). Community-level physiological profiling analyses show potential to identify the copiotrophic bacteria present in soil environments. PLoS ONE 12:e0171638. doi: 10.1371/journal.pone.0171638

Loeppmann, S., Semenov, M., Blagodatskaya, E., and Kuzyakov, Y. (2016). Substrate quality affects microbial- and enzyme activities in rooted soil. J. Plant Nutr. Soil Sci. 179, 39-47. doi: 10.1002/jpln.201400518

Lopez, B. R., Bashan, Y., and Bacilio, M. (2011). Endophytic bacteria of Mammillaria fraileana, an endemic rock-colonizing cactus of the southern Sonoran Desert. Arch. Microbiol. 193, 527-541. doi: $10.1007 / \mathrm{s} 00203-011-0695-8$

López-Escudero, F. J., and Mercado-Blanco, J. (2011). Verticillium wilt of olive: a case study to implement an integrated strategy to control a soil-borne pathogen. Plant Soil 344, 1-50. doi: 10.1007/s11104-010-0629-2

Maciá-Vicente, J. G., Rosso, L. C., Ciancio, A., Jansson, H. B., and Lopez-Llorca, L. V. (2009). Colonisation of barley roots by endophytic Fusarium equiseti and Pochonia chlamydosporia: effects on plant growth and disease. Ann. Appl. Biol. 155, 391-401. doi: 10.1111/j.1744-7348.2009.00352.x

Maldonado-González, M. M., Prieto, P., Ramos, C., and Mercado-Blanco, J. (2013). From the root to the stem: interaction between the biocontrol root 
endophyte Pseudomonas fluorescens PICF7 and the pathogen Pseudomonas savastanoi NCPPB 3335 in olive knots. Microb. Biotechnol. 6, 275-287. doi: $10.1111 / 1751-7915.12036$

Maldonado-González, M. M., Schilirò, E., Prieto, P., and Mercado-Blanco, J. (2015). Endophytic colonization and biocontrol performance of Pseudomonas fluorescens PICF7 in olive (Olea europaea L.) are determined neither by pyoverdine production nor swimming motility. Environ. Microbiol. 17, 3139-3153. doi: 10.1111/1462-2920.12725

Manaut, N., Sanguin, H., Ouahmane, L., Bressan, M., Thioulouse, J., Baudoin, E., et al. (2015). Potentialities of ecological engineering strategy based on native arbuscular mycorrhizal community for improving afforestation programs with carob trees in degraded environments. Ecol. Eng. 79, 113-119. doi: 10.1016/j.ecoleng.2015.03.007

Manzanilla-López, R. H., Esteves, I., Finetti-Sialer, M. M., Hirsch, P. R., Ward, E., Devonshire, J., et al. (2013). Pochonia chlamydosporia: advances and challenges to improve its performance as a biological control agent of sedentary endoparasitic nematodes. J. Nematol. 45, 1-7. Available online at: http://journals. fcla.edu/jon/article/view/82113

Markakis, E. A., Tjamos, S. E., Antoniou, P. P., Paplomatas, E. J., and Tjamos, E. C. (2016). Biological control of Verticillium wilt of olive by Paenibacillus alvei, strain K165. BioControl 61, 293-303. doi: 10.1007/s10526-0159669-0

Martínez-García, P. M., Ruano-Rosa, D., Schilirò, E., Prieto, P., Ramos, C., Rodríguez-Palenzuela, P., et al. (2015). Complete genome sequence of Pseudomonas fluorescens strain PICF7, an indigenous root endophyte from olive (Olea europaea L.) and effective biocontrol agent against Verticillium dahliae. Stand. Genomic Sci. 10:10. doi: 10.1186/1944-32 77-10-10

Massart, S., Perazzolli, M., Höfte, M., Pertot, I., and Jijakli, M. H. (2015). Impact of the omic technologies for understanding the modes of action of biological control agents against plant pathogens. Biocontrol 60, 725-746. doi: 10.1007/s10526-015-9686-z

Mazzola, M. (1997). Identification and pathogenicity of Rhizoctonia spp. isolated from apple roots and orchard soils. Phytopathology 87, 582-587. doi: 10.1094/PHYTO.1997.87.6.582

Mechri, B., Manga, A. G. B., Tekaya, M., Attia, F., Cheheb, H., Meriem, F. B., et al. (2014). Changes in microbial communities and carbohydrate profiles induced by the mycorrhizal fungus (Glomus intraradices) in rhizosphere of olive trees (Olea europaea L.). Appl. Soil Ecol. 75, 124-133. doi: 10.1016/j.apsoil.2013.11.001

Mei, C., and Flinn, B. S. (2010). The use of beneficial microbial endophytes for plant biomass and stress tolerance improvement. Recent Pat. Biotechnol. 4, 81-95. doi: 10.2174/187220810790069523

Mendes, R., Garbeva, P., and Raaijmakers, J. M. (2013). The rhizosphere microbiome: significance of plant beneficial, plant pathogenic, and human pathogenic microorganisms. FEMS Microbiol. Rev. 37, 634-663. doi: $10.1111 / 1574-6976.12028$

Mercado-Blanco, J. (2015). "Pseudomonas strains that exert biocontrol of plant pathogens," in Pseudomonas: Volume 7: New Aspects of Pseudomonas Biology, eds J.-L. Ramos, J. B. Goldberg and A. Filloux (Dordrecht: Springer), 121-172.

Mercado-Blanco, J., and Lugtenberg, B. (2014). Biotechnological applications of bacterial endophytes. Curr. Biotechnol. 3, 60-75. doi: $10.2174 / 22115501113026660038$

Mercado-Blanco, J., Rodríguez-Jurado, D., Hervás, A., and Jiménez-Diaz, R. M. (2004). Suppression of Verticillium wilt in olive planting stocks by root-associated fluorescent Pseudomonas spp. Biol. Control 30, 474-486. doi: $10.1016 /$ j.biocontrol.2004.02.002

Meyer, S. L. F., and Roberts, D. P. (2002). Combinations of biocontrol agents for management of plant-parasitic nematodes and soilborne plant-pathogenic fungi. J. Nematol. 34, 1-8. Available online at: http://journals.fcla.edu/jon/ article/view/69386

Milgroom, M. G., and Cortesi, P. (2004). Biological control of chestnut blight with hypovirulence: a critical analysis. Annu. Rev. Phytopathol. 42, 311-338. doi: 10.1146/annurev.phyto.42.040803.140325

Montes-Borrego, M., Navas-Cortés, J. A., and Landa, B. B. (2013). Linking microbial functional diversity of olive rhizosphere soil to management systems in commercial orchards in southern Spain. Agric. Ecosyst. Environ. 181, 169-178. doi: 10.1016/j.agee.2013.09.021
Moore, L. (1988). Use of Agrobacterium radiobacter in agricultural ecosystems. Microbiol. Sci. 5, 92-95.

Moreira, A. C., Domingos, A. C., Fontes, A. M., Semedo, J., Melo, E., Machado, H., et al. (2010). Evaluation of cork and holm oak seedling viability to Phytophthora cinnamomi infection treated with compost and mycorrhizae fungi. IOBC/WPRS Bulletin 57, 73-76.

Moyersoen, B., and Fitter, A. H. (1999). Presence of arbuscular mycorrhizas in typically ectomycorrhizal host species from Cameroon and New Zealand. Mycorrhiza 8, 247-253. doi: 10.1007/s005720050241

Mpika, J., Kébé, I. B., Issali, A. E., N'guessan, F. K., Druzhinina, S., KomonZélazowska, M., et al. (2009). Antagonist potential of Trichoderma indigenous isolates for biological control of Phytophthora palmivora the causative agent of black pod disease on cocoa (Theobroma cacao L.) in Côte d'Ivoire. African J. Biotechnol. 8, 5280-5293. Available online at: https://www.ajol.info/index.php/ ajb/article/view/65962

Müller, H., Tejedor-González, E., Mercado-Blanco, J., Rodríguez-Jurado, D., Jiménez-Díaz, R., and Berg, G. (2007). Effect of the biological control strain Serratia plymuthica HRO-C48 on Verticillium wilt of olive trees cv. Arbequina. IOBC/WPRS Bulletin 30, 173-177.

Muyzer, G., De Waal, E. C., and Uitterlinden, A. G. (1993). Profiling of complex microbial populations by denaturing gradient gel electrophoresis analysis of polymerase chain reaction-amplified genes coding for $16 \mathrm{~S}$ rRNA. Appl. Environ. Microbiol. 59, 695-700.

Ng, E. L., Bandow, C., Proença, D. N., Santos, S., Guilherme, R., Morais, P. V., et al. (2014). Does altered rainfall regime change pesticide effects in soil? A terrestrial model ecosystem study from Mediterranean Portugal on the effects of pyrimethanil to soil microbial communities under extremes in rainfall. Appl. Soil Ecol. 84, 245-253. doi: 10.1016/j.apsoil.2014.08.006

Okada, K., Okada, S., Yasue, K., Fukuda, M., and Yamada, A. (2011). Six-year monitoring of pine ectomycorrhizal biomass under a temperate monsoon climate indicates significant annual fluctuations in relation to climatic factors. Ecol. Res. 26, 411-419. doi: 10.1007/s11284-011-0800-0

Oldroyd, G. E. D. (2013). Speak, friend, and enter: signalling systems that promote beneficial symbiotic associations in plants. Nat. Rev. Microbiol. 11, 252-263. doi: $10.1038 /$ nrmicro2990

Paiva, G., Proença, D. N., Francisco, R., Verissimo, P., Santos, S. S., Fonseca, L., et al. (2013). Nematicidal bacteria associated to pinewood nematode produce extracellular proteases. PLoS ONE 8:e79705. doi: 10.1371/journal.pone.0079705

Palomares-Rius, J. E., Castillo, P., Montes-Borrego, M., Müller, H., and Landa, B. B. (2012). Nematode community populations in the rhizosphere of cultivated olive differs according to the plant genotype. Soil Biol. Biochem. 45, 168-171. doi: 10.1016/j.soilbio.2011.11.009

Palomares-Rius, J. E., Castillo, P., Montes-Borrego, M., Navas-Cortés, J. A., and Landa, B. B. (2015). Soil properties and olive cultivar determine the structure and diversity of plant-parasitic nematode communities infesting olive orchards soils in southern Spain. PLoS ONE 10:6890. doi: 10.1371/journal.pone.0116890 Pegg, G., and Brady, B. (2002). Verticillium wilts. Wallingford: CAB International. Pellegrini, A., Corneo, P. E., Camin, F., Ziller, L., Tosi, S., and Pertot, I. (2012). Studying trophic interactions between a plant pathogen and two different antagonistic microorganisms using a 13C-labeled compound and isotope ratio mass spectrometry. Rapid Commun. Mass Spectrom. 26, 510-516. doi: $10.1002 / \mathrm{rcm} .6131$

Pérez-Jiménez, R. M. (2006). A review of the biology and pathogenicity of Rosellinia necatrix - The cause of white root rot disease of fruit trees and other plants. J. Phytopathol. 154, 257-266. doi: 10.1111/j.1439-0434.2006.01101.x

Pervaiz, T., Lotfi, A., Haider, M., Haifang, J., and Fang, J. (2017). High throughput sequencing advances and future challenges. J. Plant Biochem. Physiol. 5:188. doi: 10.4172/2329-9029.1000188

Philippot, L., Raaijmakers, J. M., Lemanceau, P., and Van Der Putten, W. H. (2013). Going back to the roots: the microbial ecology of the rhizosphere. Nat. Rev. Microbiol. 11, 789-799. doi: 10.1038/nrmicro3109

Pieterse, C. M. J., Zamioudis, C., Berendsen, R. L., Weller, D. M., Van Wees, S. C. M., and Bakker, P. A. H. M. (2014). Induced systemic resistance by beneficial microbes. Annu. Rev. Phytopathol. 52, 347-375. doi: 10.1146/annurev-phyto-082712-102340

Pinto, C., and Gomes, A. C. (2016). Vitis vinifera microbiome: from basic research to technological development. Biocontrol 61, 243-256. doi: 10.1007/s10526-016-9725-4 
Ploetz, R. C. (2006). Fusarium induced diseases of tropical, perennial crops. Phytopathology 96, 648-652. doi: 10.1094/PHYTO-96-0648

Porras-Alfaro, A., Liu, K.-L., Kuske, C. R., and Xie, G. (2014). From genus to phylum: large-subunit and internal transcribed spacer rRNA operon regions show similar classification accuracies influenced by aatabase composition. Appl. Environ. Microbiol. 80, 829-840. doi: 10.1128/AEM.02894-13

Postma, J., and Goossen-van de Geijn, H. (2016). Twenty-four years of Dutch Trig ${ }^{\circledR}$ application to control Dutch elm disease. Biocontrol 61, 305-312. doi: 10.1007/s10526-016-9731-6

Prieto, P., and Mercado-Blanco, J. (2008). Endophytic colonization of olive roots by the biocontrol strain Pseudomonas fluorescens PICF7. FEMS Microbiol. Ecol. 64, 297-306. doi: 10.1111/j.1574-6941.2008.00450.x

Prieto, P., Navarro-Raya, C., Valverde-Corredor, A., Amyotte, S. G., Dobinson, K. F., and Mercado-Blanco, J. (2009). Colonization process of olive tissues by Verticillium dahliae and its in planta interaction with the biocontrol root endophyte Pseudomonas fluorescens PICF7. Microb. Biotechnol. 2, 499-511. doi: 10.1111/j.1751-7915.2009.00105.x

Prieto, P., Schilirò, E., Maldonado-González, M. M., Valderrama, R., BarrosoAlbarracín, J. B., and Mercado-Blanco, J. (2011). Root hairs play a key role in the endophytic colonization of olive roots by Pseudomonas spp. with biocontrol activity. Microb. Ecol. 62, 435-445. doi: 10.1007/s00248-011-9827-6

Proença, D. N., Francisco, R., Kublik, S., Schöler, A., Vestergaard, G., Schloter, M., et al. (2017a). The microbiome of endophytic, wood colonizing bacteria from pine trees as affected by pine wilt disease. Sci. Rep. 7:4205. doi: 10.1038/s41598-017-04141-6

Proença, D. N., Grass, G., and Morais, P. V. (2017b). Understanding pine wilt disease: roles of the pine endophytic bacteria and of the bacteria carried by the disease-causing pinewood nematode. MicrobiologyOpen 6:e00415. doi: 10.1002/mbo3.415

Radojevic, A. A., Serbula, S. M., Kalinovic, T. S., Kalinovic, J. V., Steharnik, M. M., Petrovic, J. V., et al. (2017). Metal/metalloid content in plant parts and soils of Corylus spp. influenced by mining-metallurgical production of copper. Environ. Sci. Pollut. Res. 24, 10326-10340. doi: 10.1007/s11356-017-8520-9

Rasche, F., Knapp, D., Kaiser, C., Koranda, M., Kitzler, B., ZechmeisterBoltenstern, S., et al. (2011). Seasonality and resource availability control bacterial and archaeal communities in soils of a temperate beech forest. ISME J. 5, 389-402. doi: 10.1038/ismej.2010.138

Reinhold-Hurek, B., Bünger, W., Burbano, C. S., Sabale, M., and Hurek, T. (2015). Roots shaping their microbiome: global hotspots for microbial activity. Annu. Rev. Phytopathol. 53, 403-424. doi: 10.1146/annurev-phyto-082712-102342

Roccuzzo, G., Ciancio, A., and Bonsignore, R. (1993). Population density and soil antagonists of Meloidogyne hapla infecting kiwi in southern Italy. Fundam. Appl. Nematol. 16, 151-154.

Roesch, L. F. W., Fulthorpe, R. R., Riva, A., Casella, G., Hadwin, A. K. M., Kent, A. D., et al. (2007). Pyrosequencing enumerates and contrasts soil microbial diversity. ISME J. 1, 283-290. doi: 10.1038/ismej.2007.53

Rosso, L. C., Colagiero, M., Salatino, N., and Ciancio, A. (2014). Observations on the effect of trophic conditions on Pochonia chlamydosporia gene expression. Ann. Appl. Biol. 164, 232-243. doi: 10.1111/aab.12099

Rosso, L. C., Finetti-Sialer, M. M., Hirsch, P. R., Ciancio, A., Kerry, B. R., and Clark, I. M. (2011). Transcriptome analysis shows differential gene expression in the saprotrophic to parasitic transition of Pochonia chlamydosporia. Appl. Microbiol. Biotechnol. 90, 1981-1994. doi: 10.1007/s00253-011-3282-7

Ruano-Rosa, D., and López Herrera, C. J. (2009). Evaluation of Trichoderma spp. as biocontrol agents against avocado white root rot. Biol. Control 51, 66-71. doi: 10.1016/j.biocontrol.2009.05.005

Ruano-Rosa, D., Prieto, P., Rincón, A. M., Gómez-Rodríguez, M. V., Valderrama, R., Barroso, J. B., et al. (2016). Fate of Trichoderma harzianum in the olive rhizosphere: time course of the root colonization process and interaction with the fungal pathogen Verticillium dahliae. BioControl 61, 269-282. doi: 10.1007/s10526-015-9706-z

Ruano-Rosa, D., Valverde-Corredor, A., Gómez-Lama Cabanás, C., Sesmero, R., and Mercado-Blanco, J. (2017). "What lies beneath: Root-associated bacteria to improve the growth and health of olive treestle," in Soil Biological Communities and Ecosystem Resilience, Sustainability in Plant and Crop Protection Series, eds M. Lukac, P. Grenni, and M. Gamboni (Switzerland: Springer International Publishing AG), 107-122.
Salomon, M. V., Bottini, R., de Souza Filho, G. A., Cohen, A. C., Moreno, D., Gil, M., et al. (2014). Bacteria isolated from roots and rhizosphere of Vitis vinifera retard water losses, induce abscisic acid accumulation and synthesis of defenserelated terpenes in in vitro cultured grapevine. Physiol. Plant. 151, 359-374. doi: $10.1111 /$ ppl.12117

Sanei, S. J., and Razavi, S. E. (2011). Suppression of Verticillium wilt of olive by Pseudomonas fluorescens. Am. J. Exp. Agric. 1, 294-305. doi: 10.9734/AJEA/2011/500

Santi, C., Bogusz, D., and Franche, C. (2013). Biological nitrogen fixation in non-legume plants. Ann. Bot. 111, 743-767. doi: 10.1093/aob/mct048

Scheffer, R., Voeten, J., and Guries, R. (2008). Biological control of Dutch elm disease. Plant Dis. 92, 192-200. doi: 10.1094/PDIS-92-2-0192

Schilirò, E., Ferrara, M., Nigro, F., and Mercado-Blanco, J. (2012). Genetic responses induced in olive roots upon colonization by the biocontrol endophytic bacterium Pseudomonas fluorescens PICF7. PLoS ONE 7:e48646. doi: 10.1371/journal.pone.0048646

Schlaeppi, K., Bender, S. F., Mascher, F., Russo, G., Patrignani, A., Camenzind, T., et al. (2016). High-resolution community profiling of arbuscular mycorrhizal fungi. New Phytol. 212, 780-791. doi: 10.1111/nph.14070

Sezen, K., Demir, and Demirbag, Z. (2007). Identification and pathogenicity of entomopathogenic bacteria from common cockchafer, Melolontha melolontha (Coleoptera: Scarabaeidae). New Zeal. J. Crop Hortic. Sci. 35, 79-85. doi: 10.1080/01140670709510171

Shakya, M., Gottel, N., Castro, H., Yang, Z. K., Gunter, L., Labb, J., et al. (2013). A multifactor analysis of fungal and bacterial community structure in the root microbiome of mature Populus deltoides trees. PLOS ONE 8:e76382. doi: 10.1371/journal.pone.0076382

Sharma, M. P., and Buyer, J. S. (2015). Comparison of biochemical and microscopic methods for quantification of arbuscular mycorrhizal fungi in soil and roots. Appl. Soil Ecol. 95, 86-89. doi: 10.1016/j.apsoil.2015.06.001

Sharpton, T. J. (2014). An introduction to the analysis of shotgun metagenomic data. Front. Plant Sci. 5:209. doi: 10.3389/fpls.2014.00209

Sheng, M., Tang, M., Chen, H., Yang, B., Zhang, F., and Huang, Y. (2008). Influence of arbuscular mycorrhizae on photosynthesis and water status of maize plants under salt stress. Mycorrhiza 18, 287-296. doi: 10.1007/s00572-0080180-7

Shin, S., Lv, J., Fazio, G., Mazzola, M., and Zhu, Y. (2014). Transcriptional regulation of ethylene and jasmonate mediated defense response in apple (Malus domestica) root during Pythium ultimum infection. Hortic. Res. 1:14053. doi: 10.1038/hortres.2014.53

Simpson, J., Picchi, G., Gordon, A., Thevathasan, N., Stanturf, J., and Nicholas, I. (2009). "Environmental benefits associated with short-rotation woody crops. Technical Review No. 3," in IEA Bioenergy Task 30: Short Rotation Crops for Bioenergy Systems, 1-23. Available online at: https://www.yumpu.com/en/ document/view/7259480/technical-review-no-3-short-rotation-crops

Singer, E., Bushnell, B., Coleman-Derr, D., Bowman, B., Bowers, R.M., Levy, A., et al. (2016). High-resolution phylogenetic microbial community profiling. ISME J. 10, 2020-2032. doi: 10.1038/ismej.2015.249

Singh, K.P., Jaiswal, R.K., and Kumar, N. (2007). Catenaria anguillulae Sorokin: a natural biocontrol agent of Meloidogyne graminicola causing root knot disease of rice (Oryza sativa L.). World J. Microbiol. Biotechnol. 23, 291-294. doi: 10.1007/s11274-006-9210-9

Sipos, G., Prasanna, A.N., Walter, M.C., O’Connor, E., Bálint, B., Krizsán, K., et al. (2017). Genome expansion and lineage-specific genetic innovations in the forest pathogenic fungi Armillaria. Nat. Ecol. Evol. 1, 1931-1941. doi: 10.1038/s41559-017-0347-8

Söderberg, K.H., Probanza, A., Jumpponen, A., and Bååth, E. (2004). The microbial community in the rhizosphere determined by community-level physiological profiles (CLPP) and direct soil- and cfu-PLFA techniques. Appl. Soil Ecol. 25, 135-145. doi: 10.1016/j.apsoil.2003.08.005

Steddom, K., Becker, O., and Menge, J. (2002). Repetitive applications of the biocontrol agent Pseudomonas putida 06909-rif/nal and effects on populations of Phytophthora parasitica in citrus orchards. Phytopathology 92, 850-856. doi: 10.1094/PHYTO.2002.92.8.850

Stefanowicz, A. (2006). The biolog plates technique as a tool in ecological studies of microbial communities. Polish J. Environ. Stud. 15, 669-676. Available online at: https://www.pjoes.com/pdf/15.5/669-676.pdf 
Stella, A.-B. (2014). Reverse transcriptase-quantitative polymerase chain reaction (RT-qPCR) and its usefulness in soil microbial ecological studies - a review. African J. Biotechnol. 13, 723-728. doi: 10.5897/AJBX2013.13563

Steward, G.F., and Rappé, M.S. (2007). What's the "meta" with metagenomics? ISME J. 1, 100-102. doi: 10.1038/ismej.2007.25

Stock, S.P. (2015). "Diversity, biology and evolutionary relationships," in Nematode Pathogenesis of Insects and Other Pests: Ecology and Applied Technologies for Sustainable Plant and Crop Protection, ed R. Campos-Herrera (Switzerland: Springer International Publishing), 3-27.

Sun, H., Korhonen, K., Hantula, J., Asiegbu, F.O., and Kasanen, R. (2009). Use of a breeding approach for improving biocontrol efficacy of Phlebiopsis gigantea strains against Heterobasidion infection of Norway spruce stumps. FEMS Microbiol. Ecol. 69, 266-273. doi: 10.1111/j.1574-6941.2009. 00711.x

Sun, L.N., Zhang, Y.F., He, L.Y., Chen, Z.J., Wang, Q.Y., Qian, M., et al. (2010). Genetic diversity and characterization of heavy metal-resistantendophytic bacteria from two copper-tolerant plant species on copper mine wasteland. Bioresour. Technol. 101, 501-509. doi: 10.1016/j.biortech.2009. 08.011

Sztejnberg, A., Freeman, S., Chet, I., and Katan, J. (1987). Control of Rosellinia necatrix in soil and in apple orchard by solarization and Trichoderma harzianum. Plant Dis. 71, 365-369. doi: 10.1094/PD-71-0365

Tardif, S., Yergeau, É., Tremblay, J., Legendre, P., Whyte, L.G., and Greer, C.W. (2016). The willow microbiome is influenced by soil petroleumhydrocarbon concentration with plant compartment-specific effects. Front. Microbiol. 7:1363. doi: 10.3389/fmicb.2016.01363

Tewoldemedhin, Y.T., Mazzola, M., Botha, W.J., Spies, C.F.J., and McLeod, A. (2011). Characterization of fungi (Fusarium and Rhizoctonia) and oomycetes (Phytophthora and Pythium) associated with apple orchards in South Africa. Eur. J. Plant Pathol. 130, 215-229. doi: 10.1007/s10658-0119747-9

Thijs, S., Sillen, W., Rineau, F., Weyens, N., and Vangronsveld, J. (2016). Towards an enhanced understanding of plant-microbiome interactions to improve phytoremediation: engineering the metaorganism. Front. Microbiol. 7:341. doi: 10.3389/fmicb.2016.00341

Thijs, S., Van Dillewijn, P., Sillen, W., Truyens, S., Holtappels, M., D'Haen, J., et al. (2014). Exploring the rhizospheric and endophytic bacterial communities of Acer pseudoplatanus growing on a TNT-contaminated soil: towards the development of a rhizocompetent TNT-detoxifying plant growth promoting consortium. Plant Soil 385, 15-36. doi: 10.1007/s11104-0142260-0

Tiedje, J. M., Asuming-Brempong, S., Nusslein, K., Marsh, T. L., and Flynn, S.J. (1999). Opening the black box of soil microbial diversity. Appl. Soil Ecol. 109-122. doi: 10.1016/S0929-1393(99)00026-8

Triki, M. A., Krid Hadj-Taieb, S., Hammami Mellouli, I., Rhouma, A., Gdoura, R., and Hassairi, A. (2012). Identification and screening of bacterial isolates from Saharan weeds for Verticillium dahliae control. J. Plant Pathol. 94, 305-311. doi: 10.4454/JPP.FA.2012.029

Trivedi, P., Trivedi, C., Grinyer, J., Anderson, I.C., and Singh, B.K. (2016). Harnessing host-vector microbiome for sustainable plant disease management of phloem-limited bacteria. Front. Plant Sci. 7:1423. doi: $10.3389 /$ fpls.2016.01423

Turner, T.R., Ramakrishnan, K., Walshaw, J., Heavens, D., Alston, M., Swarbreck, D., et al. (2013). Comparative metatranscriptomics reveals kingdom level changes in the rhizosphere microbiome of plants. ISME J. 7, 2248-2258. doi: 10.1038/ismej.2013.119

Urbanová, M., Šnajdr, J., and Baldrian, P. (2015). Composition of fungal and bacterial communities in forest litter and soil is largely determined by dominant trees. Soil Biol. Biochem. 84, 53-64. doi: 10.1016/j.soilbio.2015.02.011

Urich, T., Lanzén, A., Qi, J., Huson, D. H., Schleper, C., and Schuster, S. C. (2008). Simultaneous assessment of soil microbial community structure and function through analysis of the meta-transcriptome. PLOS ONE 3:e2527. doi: 10.1371/journal.pone.0002527

Uroz, S., Oger, P., Tisserand, E., CéBron, A., Turpault, M.P., Bue,é, M., et al. (2016). Specific impacts of beech and Norway spruce on the structure and diversity of the rhizosphere and soil microbial communities. Sci. Rep. 6:27756. doi: $10.1038 /$ srep 27756
Van Aken, B., Yoon, J.M., and Schnoor, J. L. (2004). Biodegradation of nitro-substituted explosives 2,4,6-trinitrotoluene, hexahydro-1,3,5trinitro-1,3,5-triazine, and octahydro-1,3,5,7-tetranitro-1,3,5-tetrazocine by a phytosymbiotic Methylobacterium sp. associated with poplar tissues (Populus deltoides $\times$ nigra DN34). Appl. Environ. Microbiol. 70, 508-517. doi: 10.1128/AEM.70.1.508-517.2004

van Dam, N.M., and Bouwmeester, H.J. (2016). Metabolomics in the rhizosphere: tapping into belowground chemical communication. Trends Plant Sci. 21, 256-265. doi: 10.1016/j.tplants.2016.01.008

Vandekerckhove, T.T.M., Willems, A., Gillis, M., and Coomans, A. (2000). Occurrence of novel verrucomicrobial species, endosymbiotic and associated with parthenogenesis in Xiphinema americanum-group species (Nematoda, Longidoridae). Int. J. Syst. Evol. Microbiol. 50, 2197-2205. doi: 10.1099/00207713-50-6-2197

VanInsberghe, D., Hartmann, M., Stewart, G.R., and Mohn, W.W. (2013). Isolation of a substantial proportion of forest soil bacterial communities detected via pyrotag sequencing. Appl. Environ. Microbiol. 79, 2096-2098. doi: 10.1128/AEM.03112-12

Vervaeke, P., Luyssaert, S., Mertens, J., Meers, E., Tack, F.M.G., and Lust, N. (2003). Phytoremediation prospects of willow stands on contaminated sediment: a field trial. Environ. Pollut. 126, 275-282. doi: 10.1016/S0269-7491(03)00189-1

Vervoort, M. T. W., Vonk, J. A., Mooijman, P. J. W., van den Elsen, S. J. J., van Megen, H. H. B., Veenhuizen, P., et al. (2012). SSU ribosomal DNA-based monitoring of nematode assemblages reveals distinct seasonal fluctuations within evolutionary heterogeneous feeding guilds. PLOS ONE 7:e47555. doi: 10.1371/journal.pone.0047555

Vieira dos Santos, M.C., Curtis, R.H.C., and Abrantes, I. (2013). Effect of plant elicitors on the reproduction of the root-knot nematode Meloidogyne chitwoodi on susceptible hosts. Eur. J. Plant Pathol. 136, 193-202. doi: 10.1007/s10658-012-0155-6

Vieira dos Santos, M. C., Esteves, I., Kerry, B., and Abrantes, I. (2014). Interactions between Pochonia chlamydosporia and Meloidogyne chitwoodi in a crop rotation scheme. Nematropica 1,37-46. Available online at: http://journals.fcla. edu/nematropica/article/view/83315/0

Wang, Y., Li, Q., Shi, J., Lin, Q., Chen, X., Wu, W., et al. (2008). Assessment of microbial activity and bacterial community composition in the rhizosphere of a copper accumulator and a non-accumulator. Soil Biol. Biochem. 40, 1167-1177. doi: 10.1016/j.soilbio.2007.12.010

Weber, R.W.S., Sulzer, F.-L., and Haarhaus, M. (2004). Pythium undulatum, cause of root rot of Abies procera Christmas trees and Pseudotsuga menziesii in Northern Germany. Mycol. Prog. 3, 179-188. doi: 10.1007/s11557-0060087-7

Weiland, J.E., Beck, B.R., and Davis, A. (2013). Pathogenicity and virulence of Pythium species obtained from forest nursery soils on Douglas-Fir seedlings. Plant Dis. 97, 744-748. doi: 10.1094/PDIS-09-12-0895-RE

Weller, D., Thomashow, L., and Cook, R. (1995). "Biological control of soilborne pathogens of wheat: benefits, risks and current challenges," in Biological Control: Benefits and Risks, eds H. Hokkanen and J. Lynch (Cambridge, UK: Cambridge University Press), 149-160.

Wenzel, W.W. (2009). Rhizosphere processes and management in plantassisted bioremediation (phytoremediation) of soils. Plant Soil 321, 385-408. doi: 10.1007/s11104-008-9686-1

Weyens, N., Truyens, S., Dupae, J., Newman, L., Taghavi, S., Van Der Lelie, D., et al. (2010). Potential of the TCE-degrading endophyte Pseudomonas putida W619-TCE to improve plant growth and reduce TCE phytotoxicity and evapotranspiration in poplar cuttings. Environ. Pollut. 158, 2915-2919. doi: 10.1016/j.envpol.2010.06.004

Winding, A., Hund-Rinke, K., and Rutgers, M. (2005). The use of microorganisms in ecological soil classification and assessment concepts. Ecotoxicol. Environ. Saf. 62, 230-248. doi: 10.1016/j.ecoenv.2005.03.026

Woreta, D. (2015). Control of cockchafer Melolontha spp. grubs - A review of methods. Folia For. Pol. Ser. A 57, 33-41. doi: 10.1515/ffp2015-0005

Yang, Y., Yang, E., An, Z., and Liu, X. (2007). Evolution of nematode-trapping cells of predatory fungi of the Orbiliaceae based on evidence from rRNA-encoding DNA and multiprotein sequences. Proc. Natl. Acad. Sci. U.S.A. 104, 8379-8384. doi: $10.1073 /$ pnas.0702770104 
Zalesny, R.S., Stanturf, J.A., Gardiner, E.S., Bañuelos, G.S., Hallett, R.A., Hass, A., et al. (2016). Environmental technologies of woody crop production systems. Bioenergy Res. 9, 492-506. doi: 10.1007/s12155-016-9738-y

Zamioudis, C., and Pieterse, C.M.J. (2012). Modulation of host immunity by beneficial microbes. Mol. Plant Microbe Interact. 25, 139-150. doi: 10.1094/MPMI-06-11-0179

Zeng, H.C., Ho, H.H., and Zheng, F.C. (2005). Pythium vexans causing patch canker of rubber trees on Hainan Island, China. Mycopathologia 159, 601-606. doi: 10.1007/s11046-005-5258-6

Zhang, W., Li, F., and Nie, L. (2010). Integrating multiple "omics" analysis for microbial biology: application and methodologies. Microbiology 156, 287-301. doi: 10.1099/mic.0.034793-0

Złoch, M., Kowalkowski, T., Tyburski, J., and Hrynkiewicz, K. (2017). Modeling of phytoextraction efficiency of microbially stimulated Salix dasyclados L. in the soils with different speciation of heavy metals. Int. J. Phytoremediation 19, 1150-1164. doi: 10.1080/15226514.2017.1328396

Conflict of Interest Statement: The authors declare that the research was conducted in the absence of any commercial or financial relationships that could be construed as a potential conflict of interest.

Copyright (๑) 2018 Mercado-Blanco, Abrantes, Barra Caracciolo, Bevivino, Ciancio, Grenni, Hrynkiewicz, Kredics and Proença. This is an open-access article distributed under the terms of the Creative Commons Attribution License (CC BY). The use, distribution or reproduction in other forums is permitted, provided the original author(s) and the copyright owner are credited and that the original publication in this journal is cited, in accordance with accepted academic practice. No use, distribution or reproduction is permitted which does not comply with these terms. 